INSTITUT NATIONAL DE LA STATISTIQUE ET DES ETUDES ECONOMIQUES

Série des Documents de Travail du CREST

(Centre de Recherche en Economie et Statistique)

\author{
$n^{\circ} 2007-05$ \\ The Effect of Location on \\ Finding a Job in the Paris Region \\ L. GOBILLON \\ T. MAGNAC 2 \\ H. SELOD 3
}

Les documents de travail ne reflètent pas la position de l'INSEE et n'engagent que leurs auteurs.

Working papers do not reflect the position of INSEE but only the views of the authors.

\footnotetext{
${ }^{1}$ INED, 133 boulevard Davout, 75980 Paris Cedex 20, France. laurent.gobillon@ined.fr

2 Université de Toulouse (GREMAQ \& IDEI). Address: Manufacture des Tabacs, 21 allée de Brienne, 31000 Toulouse, France. magnac@cict.fr

3 INRA, Paris School of Economics, CREST and CEPR. Address : INRA-LEA, 48 boulevard Jourdan, 75014 Paris, France. selod@ens.fr
} 


\title{
THE EFFECT OF LOCATION ON FINDING A JOB IN THE PARIS REGION
}

\author{
Laurent GOBILLON*, Thierry MAGNAC ${ }^{* *}$ and Harris SELOD ${ }^{* * *}$
}

February 26, 2007

\begin{abstract}
There are large spatial disparities in unemployment durations across the 1,300 municipalities in the Paris region (Ile-deFrance). In order to characterize these imbalances, we estimate a proportional hazard model stratified by municipality on an exhaustive dataset of all unemployment spells starting in the first semester of 1996. This model allows us to recover a survival function for each municipality that is purged of individual observed heterogeneity. We show that only $30 \%$ of the disparities in the survival rates relate to observed individual variables. Nearly $70 \%$ of the remaining disparities are captured by local indicators, mainly segregation indices.
\end{abstract}

Key words: urban unemployment, residential segregation, spatial mismatch, duration model.

JEL classification: C41, J64, R23.

\section{Résumé}

Les durées de chômage varient beaucoup entre les 1,300 communes de l'Ile-de-France. Afin de caractériser ces disparités spatiales, nous estimons un modèle à hasard proportionnel stratifié par commune sur une base de données exhaustive des épisodes d'emploi débutant le premier semestre de l'année 1996. Ce modèle nous permet de récupérer pour chaque commune une fonction de survie purgée de l’hétérogénéité individuelle observée. Nous montrons que seuls 30\% des disparités dans les taux de survie renvoient aux variables individuelles observées. Presque $70 \%$ des disparités restantes sont captées par des indices locaux, essentiellement des indicateurs de ségrégation résidentielle.

Mots-clés: chômage urbain, ségrégation résidentielle, spatial mismatch, modèle de durée.

\footnotetext{
* Institut National d’Etudes Démographiques. Address: INED, 133 boulevard Davout, 75980 Paris Cedex, France. E-mail: laurent.gobillon@ined.fr. ** Université de Toulouse (GREMAQ \& IDEI). Address: Manufacture des Tabacs, 21 allée de Brienne, 31000 Toulouse, France. E-mail: magnac@cict.fr.

${ }^{* * *}$ INRA (PARIS-Jourdan), Paris School of Economics, CREST and CEPR. Address: INRA (PARIS-Jourdan), 48 boulevard Jourdan, 75014 Paris, France. E-mail: selod@ens.fr.
} 


\section{Introduction}

The determinants of urban unemployment have raised the interest of economists for half a century, especially in the US. In particular, two major trends of literature have tried to explain the effects of location on unemployment. The first set of works is the so-called spatial mismatch literature which investigates how distance to jobs can exacerbate unemployment among low-skilled and minority workers (see Ihlanfeldt and Sjoquist, 1998, for an empirical survey, and Gobillon, Selod and Zenou, 2007, for a theoretical one). The second set of works points out at the impact of residential segregation on the poor labor-market outcomes of ghetto residents (see e.g. Wilson, 1996, Cutler and Glaeser, 1997). In both literatures, papers usually resort to cross-section methods and try to explain individual unemployment probabilities or local unemployment rates (see e.g. Ihlanfeldt, 1993, Conley and Topa, 2002, Weinberg, 2002 and 2004).

In this paper, we focus on the local determinants of unemployment duration. Only a few papers, mainly on the US, have studied the unemployment dynamics at the individual level in a spatial perspective (Holzer, Ihlanfeldt and Sjoquist, 1994, Rogers, 1997, Dawkins, Shen and Sanchez, 2005, Johnson, 2006). Authors usually investigate the impact of local indicators proxying for spatial mismatch or residential segregation in an unemployment duration model. These papers typically estimate a proportional hazard model with a single baseline hazard common to all locations, a set of individual variables and local indicators. We adopt a much broader approach that consists in estimating a hazard function for each location while controlling for individual characteristics. This is done applying the Stratified Partial Likelihood Estimator (SPLE) proposed by Ridder and Tunali (1999).

The advantages of this method are threefold. First, we do not need to chose a specific function for the local hazard functions. We can thus measure the overall effects of location without focusing only on a few selected mechanisms, possibly proxied by criticizable local indicators. Second, we allow the effect of location to vary depending on the time spent unemployed. Hence, we can assess the effect of location on the short run (after 6 months) and on the long run (after two years). Third, we are able to evaluate what part of the overall local effect can be captured by local indicators reflecting the mechanisms put forward in the literature. This is done regressing local effects on these indicators and computing their explanatory power. 
The approach nevertheless requires a very large dataset with enough unemployment spells in each location. We thus use a unique exhaustive administrative dataset available for France on the 1993-2003 period. For tractability, we extract from this dataset unemployment spells that started in the first semester of 1996 in the Paris region (Ile-de-France). Unemployment spells can end in three different ways: finding a job, dropping out of the labor force, and right-censorship (including exits for unknown reasons). In a descriptive perspective, we compute the raw local survival functions for each type of exit using the Kaplan-Meier estimator. We find that there are very large disparities for unemployment spells that end by finding a job. Using the SPLE results, we show that only $30 \%$ of the disparities relate to individual observed characteristics. Nearly $70 \%$ of the remaining local disparities are captured by local indicators, mainly segregation indices.

The rest of the paper is structured as follows. In section 2, we provide a brief survey of the litterature on how segregation and bad physical accessibility to jobs can increase unemployment duration. Section 3 presents the data and a selection of descriptive statistics measuring spatial disparities. Section 4 details the SPLE method. Section 5 discusses the results. Finally, section 6 concludes.

\section{Why should location influence unemployment duration?}

The duration of unemployment depends on many factors. To discuss this issue in an orderly manner, it is useful to adopt a job-search perspective considering that exit from unemployment can occur at the end of a three-stage process. In the first stage, workers must wait some time before coming into contact with a job opportunity. In the second stage, an offer from the employer may materialize. Finally, the worker may accept or reject the offer depending on whether the offered wage is greater or smaller than their reservation wage. With this framework in mind, job seekers who, on average, wait long before experiencing contacts with employers and who have few chances to transform their contacts into offers and matches should experience long unemployment spells. For instance, educated workers could be advantaged in the first stage if they are more efficient in obtaining information about jobs and in contacting firms, or if labor demand is biased in their favor. They may also have an advantage in the second stage if they write better application letters and resumes and fare better during interviews. However, educated workers may be more likely 
to reject an offer when they face or anticipate many well-paid outside offers. Other individual and family characteristics such as gender, race/ethnicity, age, experience, marital status or the number and age of children and dependants should also be expected to affect unemployment duration through one or several stages of the job-acquisition process.

This section describes how location, i.e. the disconnection from job opportunities (when job opportunities are unevenly distributed within a metropolitan area) and/or residential segregation (with respect to education, race/ethnicity/nationality or employment status), can also influence the duration of unemployment. We decompose the effects on each stage of the job-acquisition process.

Disconnection from job opportunities may directly affect the time spent searching for a job in the first stage of the process. Indeed, job-seekers residing in areas with few local job vacancies or in areas located far away from employment centers are exposed only to a small pool of vacancies. Residing in loose local labor markets, they should spend more time searching before getting into contact with a potential employer. Of course, job-seekers also have the possibility to search for jobs in other areas. But having to search away from one's area of residence penalizes job seekers. At least three reasons come into view. Firstly, because of informational frictions, job-seekers may not search efficiently far away from their residences. For instance, workers residing far away from job opportunities may not hear about job offers when firms resort to recruiting methods that favor the local labor force (i.e. by posting 'wanted' signs in retail shops, or by choosing not to publicize job offers beyond a certain distance). Alternatively, job-seekers may obtain only partial information on the location of distant jobs or may have only a vague idea about the types of jobs offered in parts of the metropolitan area they are not familiar with. They may end up searching in the wrong places (Ihlanfeldt, 1997, Stoll and Raphael, 2000). Secondly, because search is costly, workers may restrict their search horizon at the vicinity of their neighborhood. They may search less often in order to reduce the number of job-search trips or may not search at all for jobs located in distant places. In this context, access to public transport or car ownership can reduce job-search costs and expand the job-search horizon (Stoll, 1999). Thirdly, the individual search effort may depend on the local cost of living so that workers residing in areas disconnected from job opportunities may not search intensively. It has been argued that workers residing in such 
areas usually incur low housing costs and thus may feel relatively little less pressure to actively search for a job in order to pay their rent (Smith and Zenou, 2003, Pattachini and Zenou, 2006).

Disconnection from job opportunities may also reduce the frequency of job proposals in the second stage. Employers may be reluctant to propose jobs to distant workers because commuting long distances would make these workers less productive (they would show up late or be tired due to excessive commuting).

Distance to job opportunities may also reduce the probability of a job acceptance in the third stage. Indeed, workers may reject a job offer that would involve commutes that are too long if commuting to that job would be too costly in view of the proposed wage (Zax and Kain, 1996). In other words, distance is likely to make the offered wage net of commuting costs drop below a worker's given reservation wage.

The effect of residential segregation on the first stage of the job-acquisition process is also likely to be harmful to the extent that job contacts often occur through friends and relatives (Mortensen and Vishwanath, 1994). Because social networks are at least partly localized, when the unemployment rate is high in a given area, workers are less likely to know employed neighbors that can let them know about existing vacancies (Calvó and Jackson, 2004, Selod and Zenou, 2006).

Residential segregation is also likely to reduce the probability for a worker residing in a segregated area to receive a job offer. This is because employers may discriminate against residentially segregated workers, a practice known as redlining (see Wilson, 1996, for stories of firms not hiring workers located in 'bad' neighborhoods). For employers, the motivation can hinge upon the stigma or prejudice associated with the residential location of candidates (sheer discrimination), or because they consider that, on average, workers from stigmatized areas have bad work habits or are more likely to be criminal (statistical discrimination). In industries and jobs in which workers are in contact with customers, employers may discriminate against residentially-segregated workers in order to satisfy the perceived prejudices of their clients, a practice known as customer discrimination (Holzer and Ihlanfeldt, 1998). In France, the issue of redlining is increasingly being put forward in the public debate to account for the unemployment of the young adults that reside in distressed areas. To our knowledge, however, the issue has not yet been studied empirically.

All these economic mechanisms suggest that the rate at which workers leave unemployment 
(which is inversely related to the duration of unemployment) depends on both individual characteristics and local features. In the present paper, we propose a methodology to disentangle individual and unspecified local effects. We explore the nature of local effects by regressing them on indices of segregation and distance to job opportunities. We assess the overall impact of these indices on finding a job, but we do not try to identify through which specific mechanisms they percolate.

\section{Description of the data}

\subsection{The area of study}

The paper focuses on the Paris region, an administrative unit of 10.9 million inhabitants distributed over 1,280 municipalities centered around the city of Paris and the 20 administrative subdistricts of Paris (which will be referred to and treated as municipalities in the analysis). These 1,300 spatial units may have very different population sizes which range from 225,000 in the most populous Parisian subdistrict to small villages located some $80 \mathrm{~km}$ away from Paris. The Paris region corresponds more or less to the Paris Metropolitan Area. ${ }^{1}$ This can be seen on Graph 1 which represents population density.

\section{[nsert Graph 1]}

As can be seen from Graph 2, the studied area exhibits large spatial disparities in the local unemployment rates across municipalities. In particular, the unemployment rates in municipalities located to the North-East of Paris are more than four times higher than in most municipalities located to the West.

[Insert Graph 2]

\footnotetext{
${ }^{1}$ The Paris region encompasses $97 \%$ of the Metropolitan Area's population, while the fraction of the Paris region population not residing in the Paris Metropolitan Area is below 1 percent (Source: 1999 Census of the Population). The reason we have chosen to work on the Paris region and not on the Paris Metropolitan Area is because the measures of job accessibility that we use in the analysis are based upon a regional survey of commuter transportion.
} 


\subsection{The ANPE historical file}

In order to study the spatial disparities in unemployment durations, we use the historical file of job applicants to the National Agency for Employment (Agence Nationale pour l'Emploi or $A N P E$ hereafter) for the Paris region. In France, most job seekers resort to the ANPE in their search for a job. This is because, in order to claim their unemployment benefits, workers who previously worked must register with the ANPE. A significant share of those who never held a job also register with the ANPE in order to find one although they are not eligible for unemployment benefits. It is estimated that in March 2002, 90\% of job seekers were registered with the ANPE (Chardon and Goux, 2003). The ANPE is organized in hundreds of local agencies and unemployed workers usually register in the agency closest to their residence. Each individual is granted a local identifier which could enable the observation of multiple duration spells as long as he stays with the same agency. However, the data does not keep track of individuals who move and change agencies. Given this restriction, we focus on single unemployment spells only.

The exhaustive dataset that we have for the Paris region contains information on the exact date of an application (the very day), the unemployment duration (in days), and the reason for which the application came to an end. Along with the municipality where the individual lives, it also provides a set of socio-economic characteristics that were reported upon registration with the employment agency: age, gender, nationality, diploma, marital status, number of children and disabilities. To build our sample, we select individuals who applied to the employment agency between January 1 and June 30, 1996 and who lived in the Paris region at that time. As we have information on unemployment spells until 2003, starting as early as 1996 enables us to follow unemployed workers over a long period and to minimize the number of incomplete spells due to the end of the observation period (which only concerns $4.83 \%$ of the exits in our sample). After deleting the very few observations for which socio-economic characteristics are missing, we end up with 430,695 observations from which we can study the exit from unemployment. More details on the construction and the contents of the dataset are given in Appendix A.

We group the different reasons given for the termination of the application with the agency into three types: (1) finding a job, (2) exiting to non-employment, and (3) right censoring (which groups unknown destinations and incomplete spells). ${ }^{2}$ A large proportion of exits are right-censored

\footnotetext{
${ }^{2}$ An exit to non-employment corresponds to either a training period, an illness, a pregnancy, a job accident (as
} 
(55.3\%). Among these right-censored observations, 29.5\% correspond to an absence at a control. In the following, we assume that right-censoring is independent of the durations until exit to a job or non-employment. ${ }^{3}$ The remaining unemployment spells mostly end up with a job (28\%) even if exit to non-employment is far from negligible (16.7\%). The average unemployment duration for individuals finding a job is 269 days whereas it stands at a higher level of 368 days for individuals who exit to non-employment. The higher unemployment duration for exits to non-employment could possibly reflect the discouragement of workers that could not find a job after a long time.

There are significant spatial disparities in the characteristics of unemployed workers in the Paris region. Table 1 reports indices of spatial disparities across municipalities for several variables of the ANPE historical file. We measure the spatial disparities in the occurence of exit types, the unemployment duration conditionally on the type of exit, and the individual variables that we use in our empirical analysis. The indices we compute are the inter-decile ratio, the inter-decile range, the Gini index and the coefficient of variation. ${ }^{4}$

We now comment the spatial disparities in the proportions of individuals who respectively experience an exit to job, an exit to non-employment, and right-censoring. For simplicity, we restrict our comments to the inter-decile ratio but other indicators give qualitatively similar results. The inter-decile ratio is fairly large for the probability that unemployment finishes with an exit to a job as it reaches 1.73 . This means that, if we order municipalities with respect to the proportion of unemployment spells ending with an exit to a job, an unemployment spell has 73 percent more chances to end with an exit to a job in the municipality at the ninth decile than in the municipality some unemployed workers can in fact work for a very small number of hours), an exemption from the rule imposing to actively search for a job, retirement, or military service. Unknown destinations can result from a change of local agency, an absence at a control, an expulsion for some misbehavior, an absence after a notification, a training or job refusal, a fake statement, the lack of a positive action to search for a job, and other unspecified cases.

${ }^{3}$ Observe that it cannot be claimed that these absences massively correspond to an applicant having found a job but neglecting to report it. A 2005 follow-up survey on a small sample of unemployed workers having left the ANPE showed that only approximately half of absentees at controls did find a job. This is not contradictory with the independence assumption.

${ }^{4}$ To compute the spatial inter-decile index of a variable, we construct the empirical distribution function of the local average of the variable. Observations are weighted by the number of unemployed in each municipality. We smooth the empirical distribution by a Gaussian kernel with a Silverman's rule-of-thumb bandwidth and deciles are retrieved using a very fine grid (1,000,000 points). 
at the first decile. The inter-decile ratio is smaller for the probability of an exit to non-employment (1.37) and for right-censoring (1.32).

If we now look at unemployment durations conditionally on the type of exit, the inter-decile ratio for unemployment spells ending with an exit to a job reaches 1.37. This means that an unemployment spell ending with an exit to a job lasts 37 percent longer in the municipality at the ninth decile than in the municipality at the first decile. For unemployment spells ending with an exit to non-employment, the inter-decile ratio is even greater and stands at 1.43.

\section{[Insert Table 1]}

We can also assess disparities between municipalities with the help of duration models. For each type of exit and for each municipality, we compute the Kaplan-Meier estimator of the survival function (which takes into account right-censorship). Disparities by exit type can then be assessed by comparing the survival function across municipalities for any chosen duration. As survival functions are well estimated only when the number of unemployed workers is large enough, we restrict our attention to municipalities with a population greater than 5,000 inhabitants in 1999 . Graph 3 represents the probability of finding a job before 24 months for each municipality of the Paris region. Disparities are large: the probability of finding a job before 24 months is below $40 \%$ in many municipalities of the North-East, whereas it is above $55 \%$ in many municipalities of the West. Graph 4 represents the probability of exiting to non-employment before 24 months for each municipality. Contrary to the graph for exit to a job, no specific pattern emerges.

\section{[Insert Graph 3 and 4]}

There are also noticeable spatial disparities in some of the socio-demographic characteristics of unemployed workers. Whereas the spatial disparities in age, sex or marital status are small (see Table 1), there are much larger disparities for some categories of nationality, education, and family size, as well as for disability. The inter-decile ratio for instance is greater than 5 for the proportion of Africans. In other words, the proportion of Africans among unemployed workers in areas in the ninth decile is 5 times greater than in areas in the first decile. The inter-decile ratio is above 5 for unemployed workers having three children or more, around 4 for unemployed workers with no diploma, and above 2.5 for disabled unemployed workers. 


\subsection{Our measures of segregation and job accessibility}

The Paris region exhibits stark socio-economic disparities which can be broadly be depicted as follows. In the North-East, the population is usually little educated, poor, and composed of blue collar workers. Recent migrant minorities are over-represented. In the West, the population is very educated, rich, and comprises mostly white collars. Minorities of recent immigration waves are under-represented. To further characterize disparities across municipalities and differences in municipality environments, we compute segregation and job-accessibility variables using several sources.

Segregation is accounted for by the municipality proportion of education and nationality groups computed from the 1999 Population Census. Job accessibility is measured by the job density around each municipality. More precisely, for each municipality we are able to identify all the other municipalities than can be reached within 45 minutes using a given transport mode (private vehicles or public transport). The 45-minute cut-off has been chosen just above the average commuting time of 34 minutes in the Paris region (DREIF-INSEE, 1997). This defines a group of municipalities for which we can calculate the overall job density (the ratio of the number of jobs located in the area to the number of occupied and unoccupied workers residing in the same area). ${ }^{5}$ Data on the location of jobs and workers are from the 1999 census. Travel times between municipalities are estimated at morning peak hours by the French Department of Transportation for 2000 using a transport survey on the Paris region (Enquête Globale de Transport).

As with the ANPE file, we compute indices of spatial disparities on these local segregation and job-accessibility variables. Results are reported in Table 2. Again, we find that spatial disparities are very pronounced for African nationalities as the inter-decile ratio is over 9 for the percentage of households from North Africa and Subsaharan Africa. It is also large for education levels and stands near 4 for the percentage of individuals with a university degree and around 2.5 for the percentage of individuals with a technical degree. Measures of job accessibility also exhibit significant spatial disparities. The inter-decile ratio for job densities by public transport is 3 .

\section{[Insert Table 2]}

In conclusion, spatial disparities of individual characteristics are assessed to be large although they

\footnotetext{
${ }^{5}$ For a discussion of alternative indicators see Gobillon and Selod (2007).
} 
differ in magnitude when considering the sample of unemployed workers (Table 1) or the whole population (Table 2). Likely sources of these differences are reporting errors and composition effects.

\section{The econometric model}

We study the effect of the local context (segregation and job accessibility) on unemployment duration using a three-stage procedure developing Ridder and Tunali (1999)'s approach. First, we specify a proportional hazard (PH hereafter) model with individual covariates and a municipalityspecific baseline hazard. Parameters related to individual variables are estimated using the stratified partial likelihood estimator (SPLE hereafter). Municipality-specific integrated baseline hazards are recovered using the Breslow estimator. Second, baseline hazards are specified as a function of municipality fixed effects which are estimated using the first-stage outputs. A final descriptive stage consists in regressing the municipality effects on local indicators of segregation (municipality composition) and job accessibility.

Our approach can be justified as follows. The first two stages allow to estimate municipality fixed effects, which would be unfeasible by maximum likelihood in one stage only for computational reasons since the number of municipalities is very large. In addition, introducing municipality fixed effects allows to properly take into account unobserved muncipality effects and thus clustering. Finally, regressing those municipality fixed effects on aggregate variables enables us to perform a variance analysis to assess the correlation of these spatial effects with segregation and job accessibility indices.

\subsection{The Stratified Partial Likelihood Estimation (SPLE)}

Consider an individual $i$ who enters unemployment (i.e. who enters the ANPE file). This individual's unemployment spell lasts until he finds a job (exit labeled $e$ ) or drops out of the labour force (exit labeled ne). The unemployment spell is right-censored if the individual disappears from the records during the observation period or has not experienced an exit before the last day of observation in the panel. A latent duration $T_{k}$ is associated to each exit $k \in\{e, n e\}$. The two latent durations and right-censorship are assumed to be independent. For an individual $i$, we 
denote $\lambda_{k}\left(\bullet \mid X_{i}, j(i)\right)$ the conditional baseline hazard rate for exit $k$ where $X_{i}$ is a set of individual explanatory variables and $j(i)$ is the municipality where the individual is located. For simplicity, we have assumed that the same set of variables conditions all latent durations. We consider a competing risk model where observations are clustered and we write the hazard function at time $t$ as:

$$
\lambda_{k}\left(t \mid X_{i}, j(i)\right)=\theta_{k}^{j(i)}(t) \exp \left(X_{i} \beta_{k}\right) \text { for } k \in\{e, n e\}
$$

where $j \in\{1, \ldots, J\}$ indexes the municipality and $\theta_{k}^{j}(t)$ is the baseline hazard rate for municipality $j$ and exit $k$. We first want to estimate the effect of individual explanatory variables using the SPLE. At this stage, we do not need to specify the municipality-specific baseline hazards as they cancel out when writing the partial likelihood function.

Denote $\Omega^{j}(t)$ the set of individuals at risk in municipality $j$ at time $t$. The probability of individual $i$ experiencing a type- $k$ exit at time $t$ conditionally on someone in the same municipality experiencing a type- $k$ exit writes: ${ }^{6}$

$$
P_{i}(t, k)=\frac{\exp \left(X_{i} \beta_{k}\right)}{\sum_{n \in \Omega^{j(i)}(t)} \exp \left(X_{n} \beta_{k}\right)}
$$

Observe that conditioning on the municipality population at risk (instead of the whole population at risk) makes all municipality effects cancel out. The stratified partial likelihood function (calculated on all those who experience an exit to a job or to non-employment) writes:

$$
L=\prod_{i} P_{i}\left(t_{i}, k_{i}\right)=\prod_{k} L_{k}\left(\beta_{k}\right)
$$

where $t_{i}$ is the time of exit of individual $i, k_{i}$ is the type of exit of individual $i$, and $L_{k}\left(\beta_{k}\right)=$ $\prod_{i \mid k_{i}=k} P_{i}\left(t_{i}, k_{i}\right)$ is constructed from all unemployment spells across clusters that end with a type- $k$ exit. $L_{k}\left(\beta_{k}\right)$ is the partial likelihood obtained in the hypothetical context where there is only one possible exit $k$ and where unemployment spells are censored if they end up with the other exit.

\footnotetext{
${ }^{6}$ This formula is true only if time is continuous. This is not the case with our data where time is expressed in days. With discrete time, the problem is that several individuals may exit the same day so that it is impossible to order them depending on their time of exit. Hence, the formula for conditional probability of experiencing a given type- $k$ exit is much more complicated. Nevertheless, following Breslow (1974), we consider (2) as an approximation of the conditional probability of exit. It comes down to assuming that when an individual exits a given day, the risk set includes all the other individuals who exit the same day.
} 
Notice that each set of parameters $\beta_{k}$ can be estimated by maximizing the corresponding term $L_{k}$ separately. Denote $\widehat{\beta}_{k}$ the estimator.

For exit $k$, the Breslow estimator of the integrated baseline hazard of cluster $j, \Theta_{k}^{j}(t)$, is then:

$$
\widehat{\Theta}_{k}^{j}(t)=\int_{0}^{t} \frac{I\left(C^{j}(s)>0\right)}{\sum_{i \in \Omega^{j}(s)} \exp \left(X_{i} \widehat{\beta}_{k}\right)} d N_{k}^{j}(s)
$$

where $I(\bullet)$ is the indicator function, $C^{j}(s)=\operatorname{card} \Omega^{j}(s)$, and $d N_{k}^{j}(s)$ is a dummy that equals one if someone in municipality $j$ experiences a type $k$-exit in an arbitrarily short period of time before date $s$ (and zero otherwise). For each $t$, the variance of $\widehat{\Theta}_{k}^{j}(t)$ can be recovered from Ridder and Tunali's formulas. ${ }^{7}$

Observe that the above desirable features of the SPLE come at the expense of overlooking unobserved individual heterogeneity, whose presence can bias the estimation of the hazard rates and parameters. Latent durations associated with different types of exit might also be dependent if the effect of individual unobserved heterogeneity influencing the different types of exit are correlated. To address these issues, we might want to introduce individual unobserved heterogeneity as Lancaster (1990) who models this heterogeneity as a gamma distribution in a Cox model and estimates the parameters using an EM algorithm. But the procedure is burdensome and unfeasible in samples where the number of observations is large as in ours. An alternative way to go could be to difference out individual unobserved terms using multiple spells. In theory, this could be done by redefining clusters as couples (municipality, individual) but the number of applicants appearing twice or more is very small (about 8\%). For these reasons, we decided not to incorporate individual unobserved heterogeneity in our econometric specification (1). We nevertheless discuss the consequences of the presence of unobserved individual heterogeneity on our estimates in the empirical section and pay a particular attention to the effects of individual spatial sorting across municipalities along unobserved characteristics.

\footnotetext{
${ }^{7}$ This can be done using their equations $A 25, A 27$ and $A 29$ and setting $K=1, t_{0}=0$ and $t_{1}=T$ in their equation 22 .
} 


\subsection{The estimation of spatial effects}

In the second stage, for each type of exit, we estimate municipality fixed effects that affect the municipality-specific baseline hazards. Since the estimation procedure can be applied to each type of exit separately, we restrict our attention to a given exit $k$ and drop the subscript $k$ for readability. It should nevertheless be kept in mind that all the parameters analyzed below are exit-specific.

We assume that the municipality-specific baseline hazards take a multiplicative form:

$$
\theta^{j}(t)=\alpha^{j} \theta(t)
$$

where $\alpha^{j}$ is a municipality fixed effect and $\theta(t)$ is a general baseline hazard. Here, we depart from Ridder and Tunali who adopt an additive form. Indeed, we find it more natural to use a multiplicative specification since, when combining (1) and (5), we obtain a proportional hazard model.

Instead of directly implementing the functional estimation of (5), we divide the period $[0, \infty[$ into $M$ intervals, whose lower bound (resp. upper bound) is $t_{m-1}\left(\right.$ resp. $t_{m}$ ), for $m=1, \ldots, M$ (where $t_{0}=0$ and $t_{M}=\infty$ ). If we denote $\theta_{m}=\frac{1}{t_{m}-t_{m-1}} \int_{t_{m-1}}^{t_{m}} \theta(s) d s$ the average baseline hazard over the interval $m$, the average hazard rate over a time interval $m$ is given by

$$
y_{m}^{j}=\frac{1}{t_{m}-t_{m-1}}\left[\Theta^{j}\left(t_{m}\right)-\Theta^{j}\left(t_{m-1}\right)\right]=\alpha^{j} \theta_{m}
$$

Denote $d_{m}^{j}=\int_{t_{m-1}}^{t_{m}} I\left(C^{j}(s)>0\right) d s$ the length of time within interval $m$ when at least one individual in municipality $j$ is at risk. An estimate of the average hazard rate $y_{m}^{j}$ can be constructed from equation (4) and writes:

$$
\hat{y}_{m}^{j}=\frac{1}{d_{m}^{j}}\left[\widehat{\Theta}^{j}\left(t_{m}\right)-\widehat{\Theta}^{j}\left(t_{m-1}\right)\right]
$$

Using equation (5), we can now set up the estimated model as a minimum distance problem (or asymptotic least squares, see Gouriéroux, Monfort, and Trognon, 1985) by writing that:

$$
\ln \left(\hat{y}_{m}^{j}\right)=\ln \left(\alpha^{j}\right)+\ln \left(\theta_{m}\right)+\varepsilon_{m}^{j}
$$

where $\varepsilon_{m}^{j}=\ln \left(\hat{y}_{m}^{j}\right)-\ln \left(y_{m}^{j}\right)$ is the residual due to the sampling variability of estimated hazard rates (see Appendix B.1 for the computation of the covariance matrix following Ridder and Tunali, 1999). 
There are two statistical issues of importance. First, note that (6) is not well-defined when $\widehat{y}_{m}^{j}$ takes the value zero. This happens when there is no exit of type $k$ in municipality $j$ in the time interval $\left[t_{m-1}, t_{m}\right]$. Corresponding observations are ignored in the estimation. It is a small sample issue that can be safely ignored if the municipality-specific baseline hazards are strictly positive at all dates, the number of observations is large in most municipalities, and the intervals are large enough. In practice, there is a trade-off when choosing the intervals: whereas defining large intervals reduces the bias, it may aggregate the information too much. Conversely, defining small and numerous intervals makes a better use of the information but induces a larger bias.

Second, equation (6) is a two-component panel model that can be estimated using weighted least squares where the weights are given by the square root of the inverse of the covariance matrix of residuals $\varepsilon_{m}^{j}$ (see Appendix B.2. for computational details). However, this minimum distance estimator is known to perform badly in small samples. So we chose to use a slight modification of the equally weighted estimator which is simpler and better behaved (Altonji and Segal, 1996). ${ }^{8}$ We simply weight the estimation by the number of unemployed workers at risk at the beginning of the intervals in the municipalities. Indeed, the average hazard rate computed for any given time interval (the dependent variable in (6)) is usually computed with more accuracy when the number of unemployed workers at risk is large.

The final descriptive stage consists in regressing municipality fixed effects on aggregate explanatory variables at the municipality level. We specify:

$$
\ln \left(\alpha^{j}\right)=Z^{j} \gamma+\eta^{j}
$$

where $Z^{j}$ are municipality variables and $\eta^{j}$ are random terms. As municipality fixed effects are estimated in the previous stages, their exact value is not observed. Introducing these estimators in equation (7), we obtain:

$$
\widehat{\ln \left(\alpha^{j}\right)}=Z^{j} \gamma+\eta^{j}+\xi^{j}
$$

where $\xi^{j}=\widehat{\ln \left(\alpha^{j}\right)}-\ln \left(\alpha^{j}\right)$ is a sampling error. Equation (8) is estimated using weighted least square where the weight is the initial number of unemployed workers in the municipality. This weighting has two justifications. First, the sampling error decreases with the number of unemployed workers. Second, weighting by the number of unemployed workers can be justified if we assume

\footnotetext{
${ }^{8}$ Correcting small sampling biases by bootstrap or jackknife does not perform better (Horowitz, 1998).
} 
that municipalities can be decomposed into smaller areas of fixed population in which exit from unemployment is subject to an idiosyncratic shock with variance $\sigma^{2}$ (but affected in the same way by municipality variables). In this context, the aggregate random term $\eta^{j}$ at the municipality level in equation (7) is an average of the smaller areas' idiosyncratic shocks. We thus assume that the terms $\eta^{j}$ have a variance of the form $\sigma^{2} / C^{j}(0)$ where $C^{j}(0)$ is the initial number of unemployed workers in municipality $j$.

\section{The results}

We now comment the estimates obtained in the various stages of the econometric model. We first examine the estimated coefficients of individual explanatory variables obtained using the stratified partial likelihood estimator (stage 1). We then describe the spatial disparities in municipality survival functions obtained from the model. Finally, we compute the municipality fixed effects (stage 2) and regress them on local variables measuring residential segregation and job accessibility (stage 3$)$.

\subsection{The individual determinants of unemployment duration}

Table 3 reports the coefficients estimated using SPLE for each type of exit (job and non-employment). Remember that the effects of individual variables should be interpreted as affecting multiplicatively the hazard rates (through the term $\exp \left(X_{i} \beta\right)$ in $(1)$ ).

\section{[Insert Table 3]}

Results are as expected although the magnitude of the effects of some variables is surprisingly large. First, for both exits, younger people have shorter unemployment spells. Although negative and significant, the effect of age is marginally decreasing (in absolute value) as evidenced by the square term. Note that it is never positive in any reasonable age range. Second, women exit significantly more slowly to a job than men $(-18 \%)$ while their exit rate to non-employment is much larger $(+35 \%)$. Similarly, having children (whatever the number) decreases the exit rate to job and increases the exit rate to non-employment. Being in a couple significantly increases exit rates both to job and to non-employment. 
The strongest effects are for nationality. Africans and other non-European citizens have an exit rate to job that is between $45 \%$ and $66 \%$ lower than the French. Moreover, the effect of nationality variables on the hazard rate to non-employment is significant only for North Africans and the magnitude of the coefficient is much lower than for exit to job.

Education variables also have a strong effect. Overall, education affects more the exit rate to job than the exit rate to non-employment. For instance, compared to a university degree, a basic degree lowers the exit rate to job by $59 \%$ while it decreases the exit rate to non-employment by "only" $42 \%$. One explanation for this could be that the shadow wage (i.e. the opportunity cost of time in non participation) is less affected by education than market wages.

\subsection{Describing spatial disparities in unemployment duration}

We now assess the magnitude of spatial disparities in unemployment duration until finding a job or leaving to non-employment once the effect of individual variables has been controlled for. This is done by looking at the disparities between the municipality survival functions at 24 months. These functions are computed from the Breslow estimator where all individual variables are centered according to the mean in the whole region. Thus, these functions can be interpreted as the municipality survival functions of an "average" unemployed worker. Concerning exits to job, Graph 5 represents the probability of finding a job before 24 months in municipalities that hosted more than 5,000 inhabitants in 1999. Disparities are still large although to a lesser extent than what the raw data suggested (Graph 3). The probability of finding a job in municipalities located in the West is still higher than in municipalities located in the North-East. Graph 6 (model) and Graph 4 (raw data) show that, for exit to non-employment, disparities are non-negligible but there is no particular opposition between the West and the North-East.

[Insert Graphs 5 and 6]

\subsubsection{Comparing the explanatory power of individual and spatial effects}

We also want to assess the relative importance of individual characteristics and that of spatial effects in explaining the spatial disparities in unemployment duration. To do that, we resort to two complementary approaches. 
First, a direct approach is to compare indices of spatial disparities obtained from the KaplanMeier estimators and from our model. While Kaplan-Meier estimators represent the raw data and do not control for observed individual determinants of duration, the survival functions obtained from the model (as computed from the integrated hazard functions in equation (4)) do control for individual determinants. In Table 4, we report various disparity indices (inter-decile range and ratio, Gini index and coefficient of variation) of the survival functions after 6 and 24 months both for Kaplan-Meier and for the model. For exits to job, we find that individual variables explain only around $24 \%$ of spatial disparities at 6 months and around $15 \%$ at 24 months. For instance, the inter-decile ratio at 24 months is 1.503 for the Kaplan-Meier estimate, 1.426 for the survival function from the model and thus a coefficient of determination could be defined as $(.503-.426) / .503$, which is equal to $15.3 \%$. This shows that even after controling for the characteristics of local unemployed workers, spatial disparities in finding a job remain large. This is a common theme in the literature (see Maurin, 2004).

\section{[Insert Table 4]}

Note that the comparisons, which rely on the usual estimators of the survival functions, are only heuristic. Indeed, they are not based on an analytical relationship between the Kaplan-Meier estimators, the effect of individual variables and the municipality survival functions of the model.

Our second approach does not make use of the Kaplan-Meier estimator but has firmer analytical grounds. It is a variance analysis of the average integrated hazard at the municipality level. To see why such an analysis is feasible, observe that the log-integrated hazard of a given individual $i$ can be written as the sum of the effect of individual observed characteristics $X_{i} \beta$ and the logarithm of the municipality integrated hazard $\Theta^{j(i)}(t)$ :

$$
\ln \Lambda\left(t \mid X_{i}, j(i)\right)=X_{i} \beta+\ln \Theta^{j(i)}(t)
$$

When we average this equation across individuals in a given municipality $j$, we obtain the following decomposition of the average log-integrated hazard of that municipality:

$$
\frac{1}{N^{j}} \sum_{i \in \Omega^{j}(0)} \ln \Lambda\left(t \mid X_{i}, j\right)=X^{j} \beta+\ln \Theta^{j}(t)
$$


where $X^{j}$ is the municipality average of individual characteristics and $\Omega^{j}(0)$ is the initial number of unemployed workers in the municipality. In practice, the two right-hand side terms can be recovered from the first stage estimations and their sum yields an estimate of the left-hand side term.

In Table 5, we report the results of a variance analysis following equation (10) for short dura-

tions (6 months) and long durations (24 months). Averages of individual observable characteristics explain again around $30 \%$ of spatial effects in job exits. For instance at 12 months, the spatial variance of the log-integrated hazard is equal to .0508 while the spatial variance of the average log-integrated hazard in the municipality (LHS of (10)) is .0757. A pseudo-coefficient of determination is thus $(.0757-.0508) / .0757$, which is equal to $33 \%$. This confers to individual variables slightly more explanatory power than what we obtained in Table 4, although it remains quite low.

\section{[Insert Table 5]}

\subsubsection{Spatial sorting and spatial effects}

To understand what the remaining spatial disparities capture, it is useful to consider a random version of our model which departs from the previous specification to allow for the spatial sorting of individuals across municipalities depending on their unobserved characteristics. The new model writes:

$$
\ln \Lambda\left(T \mid X_{i}, j(i)\right)=\zeta_{i}
$$

with

$$
\begin{aligned}
\zeta_{i} & =E\left(\zeta_{i} \mid j\right)+\varepsilon_{i} \\
\varepsilon_{i} & \sim \text { Exponential }(1)
\end{aligned}
$$

where $\zeta_{i}$ are individual unobservables independent of individual observables $X_{i}$, and $E\left(\zeta_{i} \mid j\right)$ is the municipality average of individual unobserved characteristics (with $E\left(\zeta_{i} \mid j\right) \neq 0$ when some spatial sorting occurs). In order to fit a stratified proportional hazard specification, the term $E\left(\zeta_{i} \mid j\right)$ is moved to the left hand-side of equation (11). Integrating (5) and using its logarithm as well as (7), the municipality integrated hazard can be rewritten as:

$$
\ln \Theta^{j}(t)=\ln \Theta(t)+Z^{j} \gamma-E\left(\zeta_{i} \mid j\right)+\eta^{j}
$$


where $\Theta(t)$ is the integrated baseline hazard, $Z^{j}$ are observed municipality characteristics and $\eta^{j}$ are unobserved municipality effects. After controlling for individual observed characteristics, (12) shows that the remaining spatial disparities can be due not only to local characteristics (observed or not) but also to variations in the local average of individual unobserved characteristics. The lack of identification of these different effects is one form of the so-called reflection problem of Manski (1993).

\subsubsection{The correlation between spatial and individual effects}

Returning to the analysis of equation (10), it is also meaningful to calculate the correlations between the municipality composition effects $\left(X^{j} \beta\right)$ and the logarithm of the municipality integrated hazard $\left(\ln \Theta^{j}(t)\right)$ at 6,12 and 24 months. These correlations can be interpreted in three ways. They can reflect some sorting on observable municipality effects $\left(Z^{j} \gamma\right)$, some sorting on unobservable municipality characteristics $\left(\eta^{j}\right)$, or a correlation between the local average of individual observed variables and the local average of individual unobserved variables $\left(E\left(\zeta_{i} \mid j\right)\right)$.

The correlations are shown in Table 5. For exits to jobs, the correlation between the municipality composition effects and the municipality integrated hazard is high (for instance .49 at 12 months), whereas, for exits to non-employment, it is very small (-.05 at 12 months). In order to assess the robustness of these findings, Graph 7 plots, for exits to jobs, the locally aggregated predictor $X^{j} \beta$ as a function of the logarithm of the municipality integrated hazard $\ln \Theta^{j}$ at 24 months for municipalities with more than 10,000 inhabitants. The positive association between these variables clearly appears from these plots.

For exits to jobs, let us now interpret (using (12)) this positive correlation between the locally aggregated effect of the individual variables and the logarithm of the municipality integrated hazard. As already discussed, this correlation can be interpreted in three ways due to sorting. First, the unemployed workers who are less likely to find a job because of their observable characteristics could sort in municipalities with bad observable neighborhood attributes (for instance where there are many foreigners, as the neighborhood could be redlined by xenophobic employers). Second, they could also sort themselves in municipalities with bad unobservable attributes (for instance in municipalities which have a bad reputation among employers for some unobserved reason). Third, municipality aggregate of observed and unobserved individual characterics could be positively 
correlated (for instance workers with no diploma may be less efficient in job-search).

$$
\text { [Insert Graph 7] }
$$

Finally, we investigate whether places that enhance job finding curb exit to non-employment. To do that, we compute the correlations between the municipality integrated hazards for finding a job and for exit to non-employment at 6, 12 and 24 months (weighting by the number of unemployed workers at risk). We find that for short and medium horizons (6 and 12 months), there is little correlation between the two types of local effects (resp. -.028 and .033). However, in the long run (24 months), the correlation is positive and stands at .176. This means that in municipalities where job exits are more likely to occur, exits to non-employment are also more likely to take place. This result can be understood by comparing reservation and shadow wages. In this framework, a job exit occurs if the unemployed worker receives an offer above his reservation wage. An exit to non-employment occurs if the reservation wage declines below the shadow wage. Hence, our result would imply that the difference between the reservation wage and the shadow wage is likely to be smaller in municipalities where the unemployed are more likely to exit to a job. This could happen if municipalities where residents can find a job easily are also those where having a job is more likely. Spouses are thus more likely to become non participant because their opportunity cost of time increases with spouse's income.

\subsection{The correlation between spatial effects and local indices}

We then consider a multiplicative municipality hazard specified as the product of a municipality effect and an aggregate baseline hazard as given by Equation (5) and the development that follows. To implement this approach, we divide the time line into $M=9$ intervals, with the first eight ones lasting 90 days and the remaining one lasting the rest of the period. To assess whether the multiplicative specification is too restrictive, we compare the value of disparity indices obtained with the unspecified municipality hazard with those obtained with the multiplicative hazard (see Table 4). We find that the multiplicative hazard reproduces well spatial disparities for finding a job although it performs poorly for exit to non-employment (especially when considering the Gini indicator and the coefficient of variation). This justifies the use of municipality fixed effects as an adequate summary of completely unspecified municipality hazard curves in order to study the 
determinants of disparities for finding a job which is the focus of the paper.

In line with the theories presented in Section 2, we investigate how municipality fixed effects can be explained by segregation and job accessibility. Segregation is measured here by the composition of the municipality population by education and by nationality. Job accessibility is measured by local job density (as defined in Section 3.3).

Table 6 reports various regressions of municipality fixed effects on those spatial characteristics. We computed a pseudo- $R^{2}$ to assess the explanatory power of the model taking into account the sampling error (see Appendix B.3). When using only segregation indices as explanatory variables (column 1), we are able to explain $72.4 \%$ of the variance of municipality fixed effects. Job accessibility indices (column 2) have a much lower explanatory power since the pseudo $R^{2}$ is only 25.9\%. This suggests that spatial disparities in finding a job are more strongly associated with differences in the local level of segregation than with variations in job accessibility. When using both segregation and job accessiblity indices (column 3), the pseudo $R^{2}$ reaches $73.0 \%$.

We now comment on the coefficient of the latter regression (column 3). Large municipality effects in finding a job are associated with a large proportion of unskilled workers and of non-French citizens (especially non-maghrebine Africans). This is consistent with the existence of redlining (according to nationality and skill) as well as with a social network effect. Municipality effects in finding a job are also correlated with local job accessibility, especially by private transport, but the coefficients of both private and public job accessibility measures are negative in contradiction with the spatial mismatch theory.

\section{[Insert Table 6]}

Of course, there are some other interpretations of the results which are based on possible omitted local variables, reverse causality or sorting on individual unobservables.

There can be omitted local variables correlated with segregation or job-accessibility measures. Our surprising result for job accessibility could be explained if the related indices captured the low quality and high congestion of public services for instance.

Reverse causality can occur if local unemployment acts as an attraction or a repulsion force on population and jobs. This could affect the job accessibility measure and the segregation indices (provided that the population categories are differentially attracted or repulsed). For instance, French people may flee municipalities where the unemployment rate is high. This would increase 
the local proportion of foreigners, especially Africans and could explain the negative coefficient of the municipality proportion of Africans on finding a job.

Municipality explanatory variables can capture the local average of individual unobserved variables if there is a correlation between $Z^{j} \gamma$ and the omitted term $E\left(\zeta_{i} \mid j\right)$ that enters the residual in the regression (12). This is the case for instance when individuals with a given unobserved attribute (such as motivation to search for a job) choose their location depending on observable municipality variables (attractive residential neighborhoods with a bad job accessibility). This may explain the negative effect of the job accessibility index by public transit.

\section{Conclusion}

In this paper, we studied the spatial disparities in exits from unemployment across municipalities in the Paris region. To this end, we used a unique and exhaustive administrative dataset which contains all registered unemployment spells over the 1996-2003 period and has relevant information on some individual characteristics of unemployed workers as well as on their residential location. The dataset was merged with spatial indices of segregation and job accessibility computed from the population census and using a transport survey.

Our methodology is based on the estimation of duration models with two exits (finding a job and leaving out of the labor force) and right censorship. We first constructed measures of raw spatial disparities across municipalities from the local survival functions after 24 months, which demonstrated the existence of very large disparities across space. Interestingly, the local composition of workers' characteristics can explain only around $30 \%$ of these disparities. We then found that our local indices (especially residential segregation measures) capture nearly $70 \%$ of the remaining differences, suggesting that spatial determinants are key in the explanation of unemployment duration.

We believe that our work could be extended in two directions. A first extension would be to compute municipality survival functions by nationality group or class of diploma. This would enable us to assess the extent to which the effect of local factors might differ across groups as suggested in the recent spatial mismatch literature (Selod and Zenou, 2006). A second extension would be to study spatial disparities at a much finer scale. Indeed, our accessibility measures are only at 
the municipality level whereas accessibility can differ even between two small neighborhoods (e.g. when they are separated by a railroad). The recent literature on social networks also suggests that a significant part of social interactions linking unemployed workers to jobs may occur at a very fine geographic scale (see Bayer, Ross and Topa, 2006, and Gobillon and Selod, 2007, for empirical tests). This route could not yet be pursued in the absence of a sufficiently fine spatial identifier in our data, and we leave it for future research.

Aknowledgment: we are grateful to the participants at seminars at INRA, CREST, University of Tokyo and at the North American Meetings of the Regional Science Association International 2006. We thank the French National Employment Agency (ANPE) and the Ministry of Transport's Regional Directorate (DREIF) for providing us with the data. All remaining errors are ours.

\section{A Data appendix}

Over the 1993-2003 period, the panel contains 10,290,225 unemployment spells.

We select unemployment spells which begin between January 1 and June 30, 1996. We get a subsample of 451,191 unemployment spells. We keep only observations corresponding to unemployed workers between 16 and 54 years old. We end up with a dataset with 433,802 unemployment spells. After deleting observations with missing values and coding problems, we end up with a sample of 430,695 observations. Descriptive statistics on the variables of our final dataset are given in Table A1.

\section{B Computational details}

\section{B.1 The first-stage equation}

Here, we give the formulas to compute the standard errors of $\varepsilon_{m}^{j}$, the sampling error in equation (6) using Ridder and Tunali (1999)' appendix (RT hereafter). We first introduce the following 
notations that will be used below:

$$
\begin{aligned}
S_{j}^{0}(\beta, s) & =\sum_{i \in \Omega^{j}(s)} \exp \left(X_{i} \beta\right) \\
S_{j}^{1}(\beta, s) & =\sum_{i \in \Omega^{j}(s)} X_{i} \exp \left(X_{i} \beta\right)
\end{aligned}
$$

where $\Omega^{j}(s)$ is the set of unemployed workers still at risk in municipality $j$ at time $s$. Note that whereas $S_{j}^{0}(\beta, s)$ is a $1 \times 1$ matrix, $S_{j}^{1}(\beta, s)$ is a $1 \times K$ matrix, where $K$ is the number of explanatory variables in the first stage. We also denote $C^{j}(s)=\operatorname{card} \Omega^{j}(s)$ the number of unemployed workers still at risk in municipality $j$ at time $s$. According to RT (A28), we have:

$$
\exp \varepsilon_{m}^{j}=\eta_{m}^{j}+\frac{1}{\sqrt{N}} c_{j m}^{\prime} \xi
$$

where $N=\sum_{j} C^{j}(0)$ is the number of unemployed workers in the Paris region and:

$$
\begin{aligned}
& \eta_{m}^{j}=\frac{1}{d_{m}^{j}} \int_{t_{m-1}}^{t_{m}} I\left(C^{j}(s)>0\right)\left[\frac{1}{S_{j}^{0}(\beta, s)} d N^{j}(s)-\theta^{j}(s) d s\right] \\
& c_{j m}=-\frac{1}{d_{m}^{j}} \int_{t_{m-1}}^{t_{m}} I\left(C^{j}(s)>0\right) \frac{S_{j}^{1}\left(\beta^{*}, s\right)}{\left[S_{j}^{0}\left(\beta^{*}, s\right)\right]^{2}} d N^{j}(s) \\
& \xi=\sqrt{N}(\widehat{\beta}-\beta)
\end{aligned}
$$

where $\beta^{*}$ is a value between $\beta$ and $\widehat{\beta}$ (coming from a Taylor expansion not detailed here), $d N^{j}(s)$ is a dummy that equals one if someone in municipality $j$ experiences an exit in an arbitrarily short period of time before date $s$ (and zero otherwise), and $d_{m}^{j}=\int_{t_{m-1}}^{t_{m}} I\left(C^{j}(s)>0\right) d s$. Here, $\xi$ is uncorrelated with $\eta_{m}^{j}$. From equation (13), it is possible to get:

$$
\begin{aligned}
& V\left(\exp \varepsilon_{m}^{j}\right)=V\left(\eta_{m}^{j}\right)+c_{j m}^{\prime} V c_{j m} \\
& \operatorname{cov}\left(\exp \varepsilon_{m}^{j}, \exp \varepsilon_{n}^{k}\right)=c_{j m}^{\prime} V c_{k n} \text { for } j \neq k \text { or } m \neq n
\end{aligned}
$$

where $V=V(\widehat{\beta})$. These covariance-matrix terms of $\left(\exp \varepsilon_{m}^{j}\right)_{j, m}$ can be estimated computing estimators of all terms on the right-hand sides. An estimator of $V$ is obtained from the Fisher information matrix of SPLE. In practice, there is no need to have the theoretical formula to get 
this estimator as it is directly recovered from the estimation software. Some estimators of $V\left(\eta_{m}^{j}\right)$ and $c_{j m}$ are:

$$
\begin{array}{ll}
\widehat{V}\left(\eta_{m}^{j}\right)=\frac{1}{\left(d_{m}^{j}\right)^{2}} \int_{t_{m-1}}^{t_{m}} I\left(C^{j}(s)>0\right) \frac{1}{\left[S_{j}^{0}(\widehat{\beta}, s)\right]^{2}} d N^{j}(s) & (\text { from RT A25) } \\
\widehat{c}_{j m}=-\frac{1}{d_{m}^{j}} \int_{t_{m-1}}^{t_{m}} I\left(C^{j}(s)>0\right) \frac{S_{j}^{1}(\widehat{\beta}, s)}{\left[S_{j}^{0}(\widehat{\beta}, s)\right]^{2}} d N^{j}(s) & (\text { from RT A27) }
\end{array}
$$

These estimators have to be programmed to be computed. From the covariance matrix of $\left(\exp \varepsilon_{m}^{j}\right)_{j, m}$, we get the covariance matrix of $\left(\varepsilon_{m}^{j}\right)_{j, m}$ using the delta method.

\section{B.2 The second-stage equation}

\section{B.2.1 The formulas}

We first give some notations we use in this section. Denote $J$ the number of municipalities and $M$ the number of time intervals. For any $J M \times 1$ matrix $X, X_{j}$ refers to the $M \times 1$ matrix defined by $X_{(j-1) M+[1: M], 1}$. For any given $J M \times J M$ matrix $X, X_{j, k}$ refers to the $M \times M$ submatrix defined by $X_{(j-1) M+[1: M],(k-1) M+[1: M]}$ where $[1: M]$ is the vector of integers from 1 to $M$.

The equation to estimate is (6) where we fix $\theta_{1}=1$ to secure identification. We stack the observations of (6) and obtain:

$$
Y=A \alpha+B \theta+\varepsilon
$$

where $A$ is a $J M \times J$ matrix such that $A_{(j-1) M+m, k}=1$ if $j=k$ and $A_{(j-1) M+m, k}=0$ otherwise, $B$ is a $J M \times(M-1)$ matrix such that $B_{(j-1) M+m, l}=1$ if $m=l$ and $A_{(j-1) M+m, l}=0$ otherwise, $Y=\left(\ln y_{1}^{1}, \ldots, \ln y_{M}^{J}\right)^{\prime}$ and $\varepsilon=\left(\varepsilon_{1}^{1}, \ldots, \varepsilon_{M}^{J}\right)^{\prime}$ are some $J M \times 1$ vectors, $\alpha=\left(\ln \alpha_{1}, \ldots, \ln \alpha_{J}\right)^{\prime}$ is a $J \times 1$ vector and $\theta=\left(\ln \theta_{2}, \ldots, \ln \theta_{M}\right)^{\prime}$ is a $(M-1) \times 1$ vector.

Denote $\Delta=\operatorname{diag}\left(N_{11}, \ldots, N_{J M}\right)$ the $J M \times J M$ diagonal matrix where $N_{j m}$ is the number of unemployed workers in municipality $j$ still at risk at the beginning of interval $m$. After weighting equation (14) with $\Delta^{1 / 2}$, it becomes:

$$
\Delta^{1 / 2} Y=\Delta^{1 / 2} A \alpha+\Delta^{1 / 2} B \theta+\Delta^{1 / 2} \varepsilon
$$


Denote $W$ the projector in the dimension orthogonal to $\Delta^{1 / 2} A$. Using the first stage of the FrischWaugh theorem, we obtain the $W L S$ estimator of $\theta$ :

$$
\begin{aligned}
\widehat{\theta} & =\left(B^{\prime} \Delta^{1 / 2} W \Delta^{1 / 2} B\right)^{-1} B^{\prime} \Delta^{1 / 2} W \Delta^{1 / 2} Y \\
& =\theta+\left(B^{\prime} \Delta^{1 / 2} W \Delta^{1 / 2} B\right)^{-1} B^{\prime} \Delta^{1 / 2} W \Delta^{1 / 2} \varepsilon
\end{aligned}
$$

The second stage of the Frisch-Waugh theorem gives the $W L S$ estimator of $\alpha$ :

$$
\begin{aligned}
\widehat{\alpha} & =\left(A^{\prime} \Delta A\right)^{-1} A^{\prime} \Delta[Y-B \widehat{\theta}] \\
& =\left(A^{\prime} \Delta A\right)^{-1} A^{\prime} \Delta\left[Y-B \theta-B\left(B^{\prime} \Delta^{1 / 2} W \Delta^{1 / 2} B\right)^{-1} B^{\prime} \Delta^{1 / 2} W \Delta^{1 / 2} \varepsilon\right] \\
& =\alpha+\left(A^{\prime} \Delta A\right)^{-1} A^{\prime} \Delta\left[\varepsilon-B\left(B^{\prime} \Delta^{1 / 2} W \Delta^{1 / 2} B\right)^{-1} B^{\prime} \Delta^{1 / 2} W \Delta^{1 / 2} \varepsilon\right]
\end{aligned}
$$

Denote $\Gamma=A^{\prime} \Delta A, \Phi=B^{\prime} \Delta^{1 / 2} W \Delta^{1 / 2} B$ and $\Psi=B^{\prime} \Delta^{1 / 2} W \Delta^{1 / 2} V \Delta^{1 / 2} W \Delta^{1 / 2} B$, where $V=V(\varepsilon)$. We have:

$$
V(\widehat{\theta})=\Phi^{-1} \Psi \Phi^{-1}
$$

Also, we get:

$$
\begin{aligned}
V(\widehat{\alpha})= & \Gamma^{-1} A^{\prime} \Delta V \Delta A \Gamma^{-1} \\
& +\Gamma^{-1} A^{\prime} \Delta B V(\widehat{\theta}) B^{\prime} \Delta A \Gamma^{-1} \\
& -\Gamma^{-1} A^{\prime} \Delta\left(V \Delta^{1 / 2} W \Delta^{1 / 2} B \Phi^{-1} B^{\prime}+B \Phi^{-1} B^{\prime} \Delta^{1 / 2} W \Delta^{1 / 2} V\right) \Delta A \Gamma^{-1}
\end{aligned}
$$

\section{B.2.2 Computation}

We have:

$$
\begin{aligned}
\Phi & =\sum_{j=1}^{J}\left(W \Delta^{1 / 2} B\right)_{j}^{\prime}\left(W \Delta^{1 / 2} B\right)_{j}=\sum_{j=1}^{J} \bar{B}_{j}^{\prime} \Delta_{j, j} \bar{B}_{j} \\
\Psi & =\sum_{j, k=1}^{J}\left(W \Delta^{1 / 2} B\right)_{j}^{\prime} \Delta_{j, j}^{1 / 2} V_{j, k} \Delta_{k, k}^{1 / 2}(W \Delta B)_{k}=\sum_{j, k=1}^{J} \bar{B}_{j}^{\prime} \Delta_{j, j} V_{j, k} \Delta_{k, k} \bar{B}_{k} \\
\Gamma & =\operatorname{diag}\left[\operatorname{tr}\left(\Delta_{1,1}\right), \ldots, \operatorname{tr}\left(\Delta_{J, J}\right)\right]
\end{aligned}
$$

where for any given variable $Z_{j}$ of dimension $M \times 1, \bar{Z}_{j}$ is its counterpart centered with its weighted average: $\bar{Z}_{j}=Z_{j}-\frac{1}{\operatorname{tr}\left(\Delta_{j, j}\right)} \operatorname{tr}\left(\Delta_{j, j} Z_{j}\right)$. 
We also have:

$$
\begin{aligned}
\left(A^{\prime} \Delta V \Delta A\right)_{j, k} & =N_{j}^{\prime} V_{j, k} N_{k} \\
\left(A^{\prime} \Delta B V(\widehat{\theta}) B^{\prime} \Delta A\right)_{j, k} & =N_{j-}^{\prime} V(\widehat{\theta}) N_{k-}
\end{aligned}
$$

where $N_{j}=\left(N_{j, 1}, \ldots, N_{j, M}\right)^{\prime}$ and $N_{j-}=\left(N_{j, 2}, \ldots, N_{j, M}\right)^{\prime}$.

Moreover, $V \Delta^{1 / 2} W \Delta^{1 / 2}=\bar{V} \Delta$ where $\bar{V}$ is defined such that any of its given submatrix $\bar{V}_{j, k}$ writes: $\bar{V}_{j, k}=V_{j, k}-\frac{1}{\operatorname{tr}\left(\Delta_{j, j}\right)}\left(1_{M} \otimes N_{j}^{\prime}\right) V_{j, k}$ with $\otimes$ the Kronecker product and $1_{M}$ a $M \times 1$ matrix filled with the value 1 . Hence, we have:

$$
\left(A^{\prime} \Delta V \Delta^{1 / 2} W \Delta^{1 / 2} B \Phi^{-1} B^{\prime} \Delta A\right)_{j, k}=N_{j}^{\prime}\left(\bar{V}^{\prime} \Delta B \Phi^{-1} B^{\prime}\right)_{j, k} N_{k}
$$

Moreover, $B \Phi^{-1} B^{\prime}=J . J_{J} \otimes\left(\begin{array}{ll}0 & 0 \\ 0 & \Phi^{-1}\end{array}\right)$ with $J_{J}$ the $J \times J$ matrix filled with the value $1 / J$. Hence, $\left(\bar{V} \Delta B \Phi^{-1} B^{\prime}\right)_{j, k}=\sum_{l}(\bar{V} \Delta)_{j, l}\left(\begin{array}{ll}0 & 0 \\ 0 & \Phi^{-1}\end{array}\right)=\left(\sum_{l} \bar{V}_{j, l} \Delta_{l, l}\right)\left(\begin{array}{ll}0 & 0 \\ 0 & \Phi^{-1}\end{array}\right)$.

\section{B.3 The third-stage equation}

The third-stage equation to estimate is given by (8). When we stack the observations, we obtain:

$$
\widehat{\alpha}=Z \gamma+\eta+\xi
$$

where $\widehat{\alpha}=\left(\widehat{\ln \alpha_{1}}, \ldots, \widehat{\ln \alpha_{J}}\right)^{\prime}, \eta=\left(\eta_{1}, \ldots, \eta_{J}\right)^{\prime}$ and $\xi=\left(\xi_{1}, \ldots, \xi_{J}\right)^{\prime}$ are some $J \times 1$ vectors, and $Z=\left(Z_{1}^{\prime}, \ldots, Z_{J}^{\prime}\right)^{\prime}$ is a $J \times K$ matrix. We suppose that $\left(\eta_{j}\right)_{1, \ldots, J}$ have a covariance matrix $v^{2} Q^{-1}$ where $Q=\operatorname{diag}\left(N_{11}, \ldots, N_{J 1}\right)$. Equation (18) is estimated with weighted least squares where the weights are the square-roots of the numbers of unemployed workers at the initial date $\left(Q^{1 / 2}\right)$. The estimated coefficients write:

$$
\widehat{\gamma}=\left(Z^{\prime} Q Z\right)^{-1} Z^{\prime} Q \widehat{\alpha}
$$

and their covariance matrix is:

$$
\begin{aligned}
V(\widehat{\gamma}) & =\left(Z^{\prime} Q Z\right)^{-1} Z^{\prime} Q\left[V(\xi)+v^{2} Q^{-1}\right] Q Z\left(Z^{\prime} Q Z\right)^{-1} \\
& =\left(Z^{\prime} Q Z\right)^{-1} Z^{\prime} Q V(\xi) Q Z\left(Z^{\prime} Q Z\right)^{-1}+v^{2}\left(Z^{\prime} Q Z\right)^{-1}
\end{aligned}
$$


It is possible to construct a consistent estimator of $v^{2}$ using the residuals $\widehat{\eta+\xi}=Q^{1 / 2} \widehat{\alpha}-Q^{1 / 2} Z \widehat{\gamma}$. This estimator is found from the following calculation sequence:

$$
\widehat{\eta+\xi^{\prime}} \widehat{\eta+\xi}=(\eta+\xi)^{\prime}\left[I-Q^{1 / 2} Z\left(Z^{\prime} Q Z\right)^{-1} Z^{\prime}\right]^{\prime} Q\left[I-Z\left(Z^{\prime} Q Z\right)^{-1} Z^{\prime} Q^{1 / 2}\right](\eta+\xi)
$$

where we made the approximation (for $N$ large enough) that:

$$
\widehat{\eta+\xi^{\prime}} \widehat{\eta+\xi} \approx(\eta+\xi)^{\prime} Q(\eta+\xi)
$$

We thus have:

$$
E\left[\widehat{\eta+\xi^{\prime}} \widehat{\eta+\xi}\right] \approx v^{2} J+\operatorname{tr}[Q V(\xi)]
$$

when $V(\xi)$ has been computed from the first-stage estimation. An estimator of $v^{2}$ can then be defined as:

$$
\widehat{v}^{2}=\left[\widehat{\eta+\xi^{\prime}} \widehat{\eta+\xi}-\operatorname{tr}[Q V(\xi)]\right] / J
$$

We introduce an error rate coming from sampling error as:

$$
e r r=\frac{\operatorname{tr}[Q V(\xi)]}{\widehat{\eta+\xi^{\prime}} \widehat{\eta+\xi}}
$$

We also construct a pseudo- $R^{2}$ defined as:

$$
R_{p}^{2}=\frac{V_{Q}^{e}(Z \widehat{\gamma})}{V_{Q}^{e}(Z \widehat{\gamma})+\widehat{v}^{2} J}
$$

where $V_{Q}^{e}(\cdot)=(Z \widehat{\gamma}-\bar{Z} \widehat{\gamma})^{\prime} Q(Z \widehat{\gamma}-\bar{Z} \widehat{\gamma}) / \operatorname{tr}(Q)$ is the empirical variance obtained when weighting observations with weights $Q$ (where $\bar{Z}=\operatorname{tr}(Q Z) / \operatorname{tr} Q$ ). Note that when there is no sampling error, this pseudo- $R^{2}$ is equal to the usual $R^{2}$. 


\section{References}

[1] Altonji, J.G. et L.M. Segal, (1996), "Small Sample Bias in GMM estimation of Covariance Structures", Journal of Business \& Economic Statistics, 14(3), 353-65.

[2] Bayer P., Ross S. and G. Topa (2006), "Place of Work and Place of Residence: Informal Hiring Networks and Labor Market Outcomes", NBER Working Paper No. 11019.

[3] Breslow N.E. (1974), "Covariance Analysis of Censored Survival Data", Biometrics, 30, pp. 89-99.

[4] Calvo-Armengol A. and M. Jackson (2004), "Social networks in determining unemployment: Patterns, dynamics and inequality", American Economic Review, 94, 191-206.

[5] Chardon O. and D. Goux (2003), "The new european definition of BIT unemployment" (in French), Economie et Statistiques, 362, 67-83.

[6] Conley T. and G. Topa (2002), "Socio-economic distance and spatial patterns in unemployment", 17(4), 303-327.

[7] Cutler D. and E. Glaeser (1997), "Are Ghettos Good or Bad?", Quarterly Journal of Economics, 112, 827-872.

[8] Dawkins C., Shen Q. and T. Sanchez (2005), "Race, Space and Unemployment Duration", Journal of Urban Economics, 58, 91-113.

[9] DREIF (Direction Régionale de l'Equipement Ile-de-France) / INSEE Ile-de-France (1997), "Commutes: an increased mobility in the Ile-de-France region" (in French), 2 pages.

[10] Gobillon L. and H. Selod (2007), "The effect of segregation and spatial mismatch on unemployment: evidence from France", CEPR Working Paper 6198.

[11] Gobillon L., Selod H. and Y. Zenou (2007), "The mechanisms of spatial mismatch", Urban Studies, forthcoming (in Volume 44, Issue 13, December).

[12] Gouriéroux, C., A. Monfort, E. Renault and A. Trognon, (1985), "Asymptotic Least Squares" (in French), Annales de l'INSEE, 58, 91-122. 
[13] Holzer H. and K. Ihlanfeldt (1998) "Customer discrimination and employment outcomes for minority workers", Quarterly Journal of Economics, 113, 835-867.

[14] Holzer H., Ihlanfeldt K. and D. Sjoquist (1994), "Work, search and travel among white and black youth", Journal of Urban Economics, 35, 320-345.

[15] Horowitz, J., (1998), "Bootstrap Methods for Covariance Structures", Journal of Human Resources, 33, 39-61.

[16] Ihlanfeldt K. (1993), "Intra-urban job accessibility and Hispanic youth employment rate", Journal of Urban Economics, 33, 254-271.

[17] Ihlanfeldt K. (1997), "Information on the spatial distribution of job opportunities within Metropolitan Areas, Journal of Urban Economics, 41, 218-242.

[18] Ihlanfeldt, K. and D. Sjoquist (1998), "The spatial mismatch hypothesis: a review of recent studies and their implications for welfare reform", Housing Policy Debate, 9, 849-892.

[19] Johnson R. (2006) "Landing a job in urban space: the extent and effects of spatial mismatch", Regional Science and Urban Economics, 36, 331-72.

[20] Manski, C. F. (1993), "Identification of Endogenous Social Effects: The Reflection Problem", Review of Economic Studies, 60, 531-42.

[21] Maurin E. (2004), The French Ghetto (in French), ed. Seuil, 95p.

[22] Mortensen D. et T. Vishwanath (1994), "Personal contacts and earnings. It is who you know!", Labour Economics, 1, 187-201.

[23] Patacchini E. Y. Zenou (2006), "Search activities, cost of living, and local labor markets in Britain", Regional Science and Urban Economics, 36, 227-48.

[24] Ridder G. and I. Tunali (1999), "Stratified partial likelihood estimation", Journal of Econometrics, 92(2), 193-232.

[25] Rogers C. (1997), "Job Search and Unemployment Duration: Implications for the Spatial Mismatch Hypothesis", Journal of Urban Economics, 42, 109-32. 
[26] Selod H. and Y. Zenou (2006), "City structure, job search, and labor discrimination. Theory and policy implications", Economic Journal, 116, 1057-87.

[27] Smith T. and Y. Zenou (2003), "Spatial mismatch, search effort and urban spatial structure", Journal of Urban Economics, 54, 129-156.

[28] Stoll M. (1999), "Spatial job search, spatial mismatch, and the employment and wages of racial and ethnic groups in Los Angeles", Journal of Urban Economics, 46, 129-55.

[29] Stoll M. and S. Raphael (2000), "Racial differences in spatial job search patterns: Exploring the causes and consequences", Economic Geography, 201-223.

[30] Weinberg B. (2000), "Black residential centralization and the spatial mismatch hypothesis", Journal of Urban Economics, 48, pp. 110-134.

[31] Weinberg B. (2094), "Testing the spatial mismatch hypothesis using inter-city variations in industrial composition", Regional Science and Urban Economics, 34, 505-32.

[32] Wilson, J. (1996), When Work Disappears: The World of the New Urban Poor, New York: Alfred A. Knopf.

[33] Zax J. and J. Kain (1996), "Moving to the suburbs: Do relocating companies leave their Black employees behind?", Journal of Labor Economics, 14, 472-504. 
Graph 1: Population density (per sq km) in the Paris region in 1999

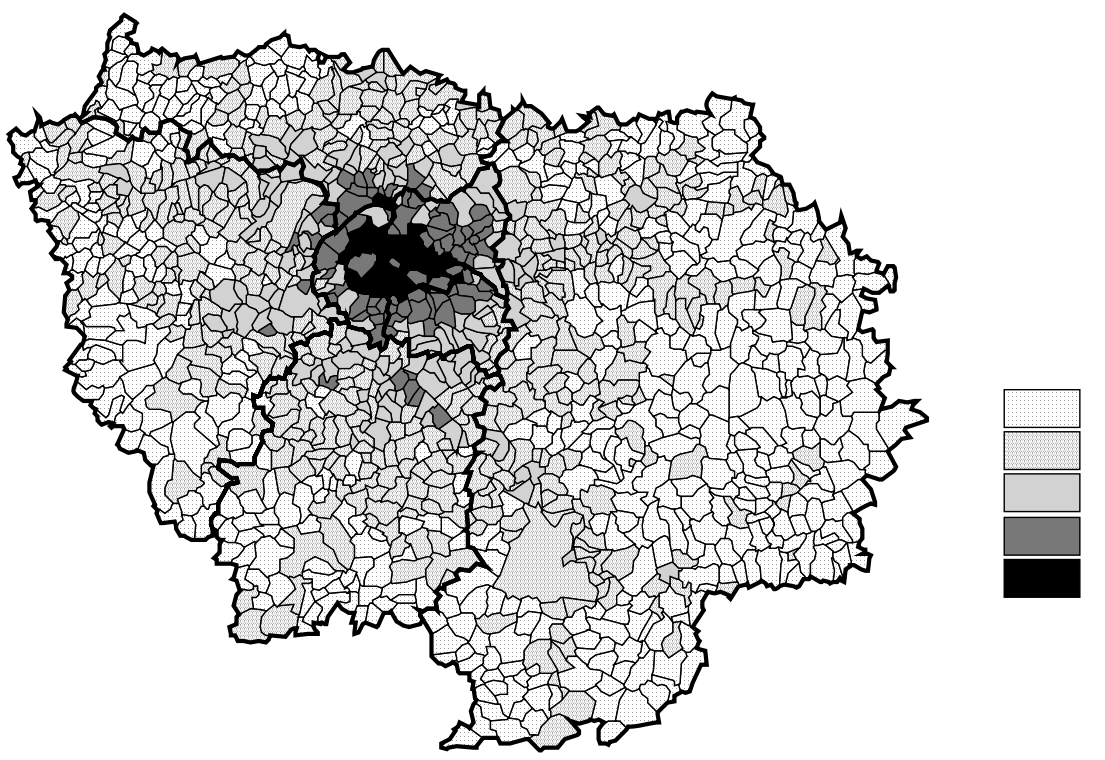

less than 100

100 to 1,500

1,500 to 5,000

5,000 to 10,000

over 10,000

Source: constructed from the 1999 Population Census, INSEE. The geographical unit is the subdistrict for the city of Paris or the municipality for the rest of the region. Bold lines represent the boundaries of the city of Paris (the turtle-shaped area in the middle of the map) and of the seven surrounding subregional administrative districts (départements).

Graph 2: Unemployment rates in the Paris region in 1999

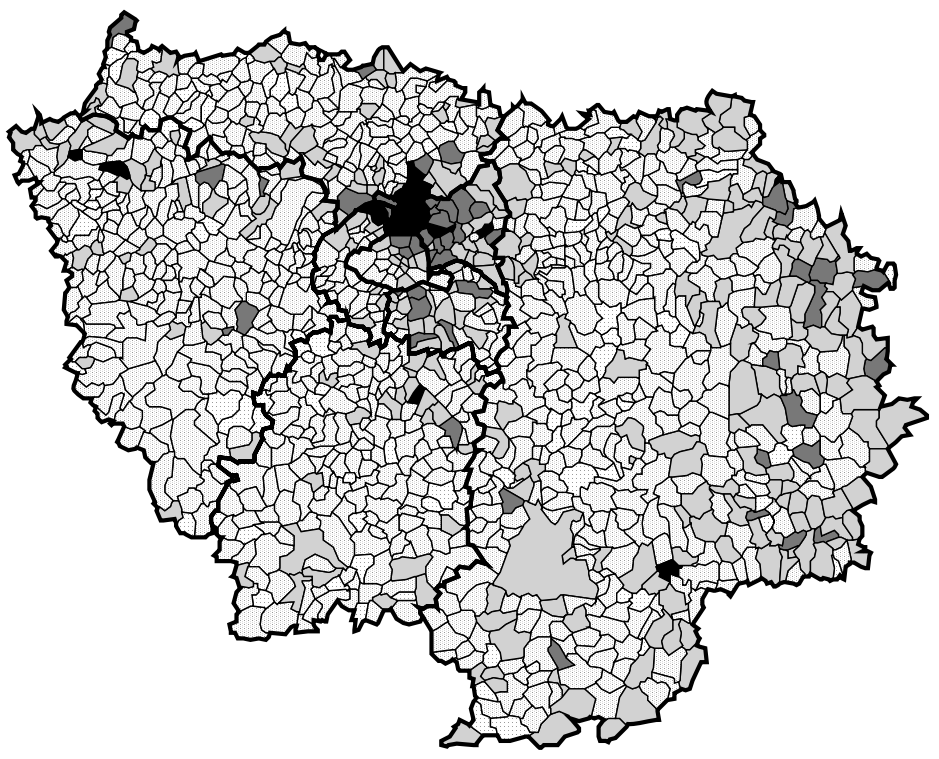

less than $5 \%$

$5-10 \%$

$10-15 \%$

$15-20 \%$

above $20 \%$ 
Graph 3: Probability of finding a job before 24 months (Kaplan-Meier) for municipalities with at least 5,000 inhabitants

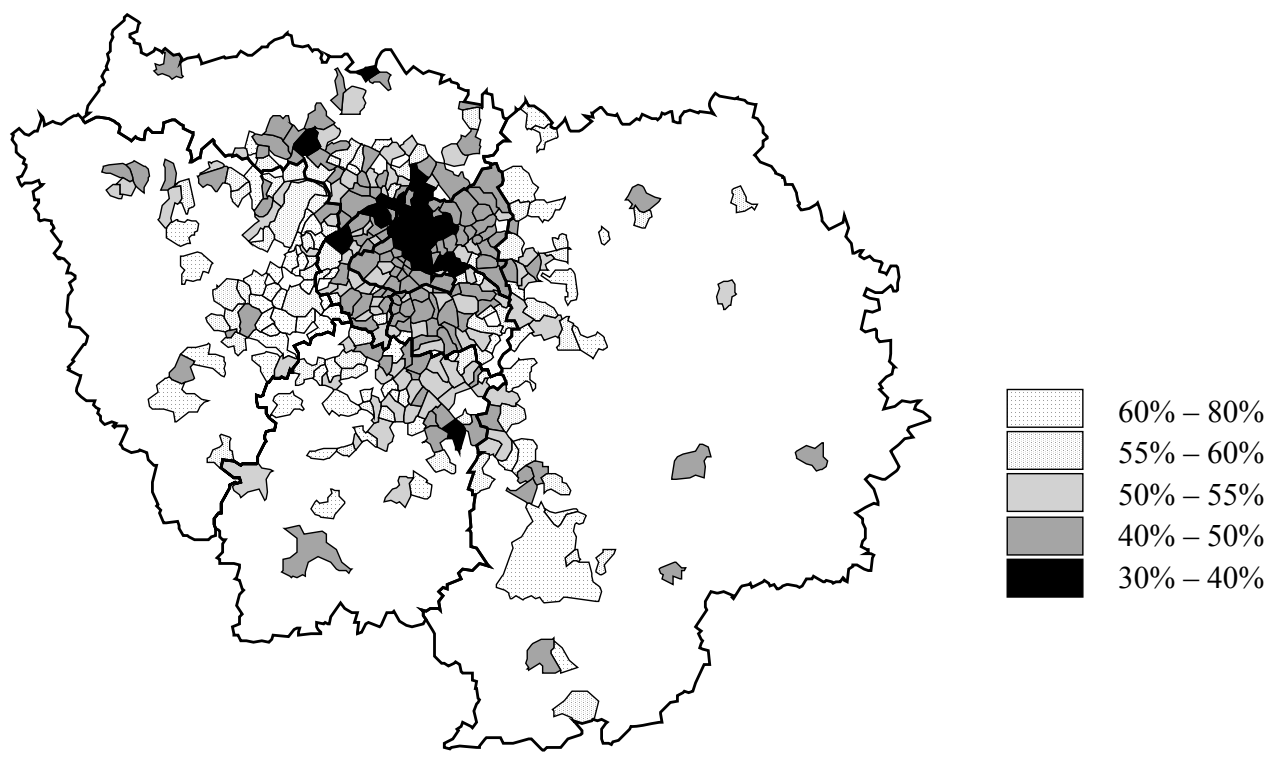

Source: constructed from the ANPE file.

Graph 4: Probability of leaving for non-employment before 24 months (Kaplan-Meier) for municipalities with at least 5,000 inhabitants

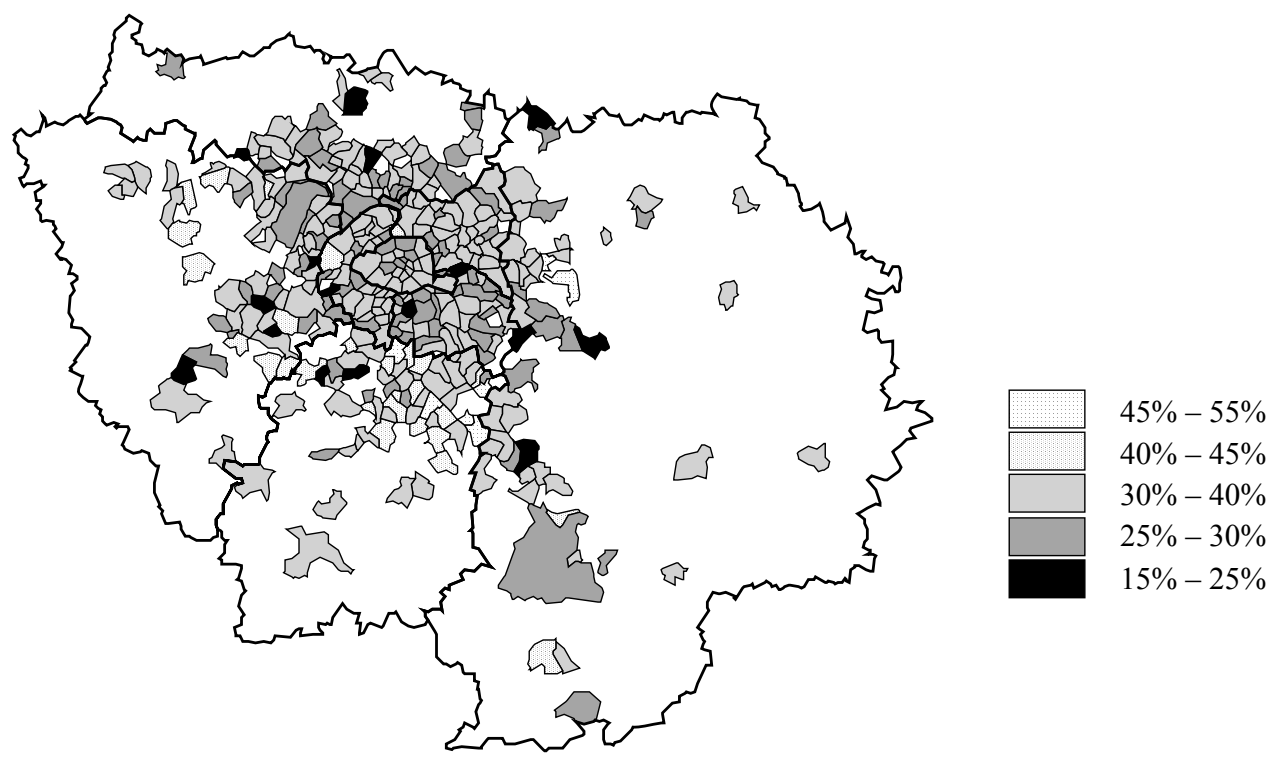


Graph 5: Probability of finding a job before 24 months (model) for municipalities with at least 5,000 inhabitants

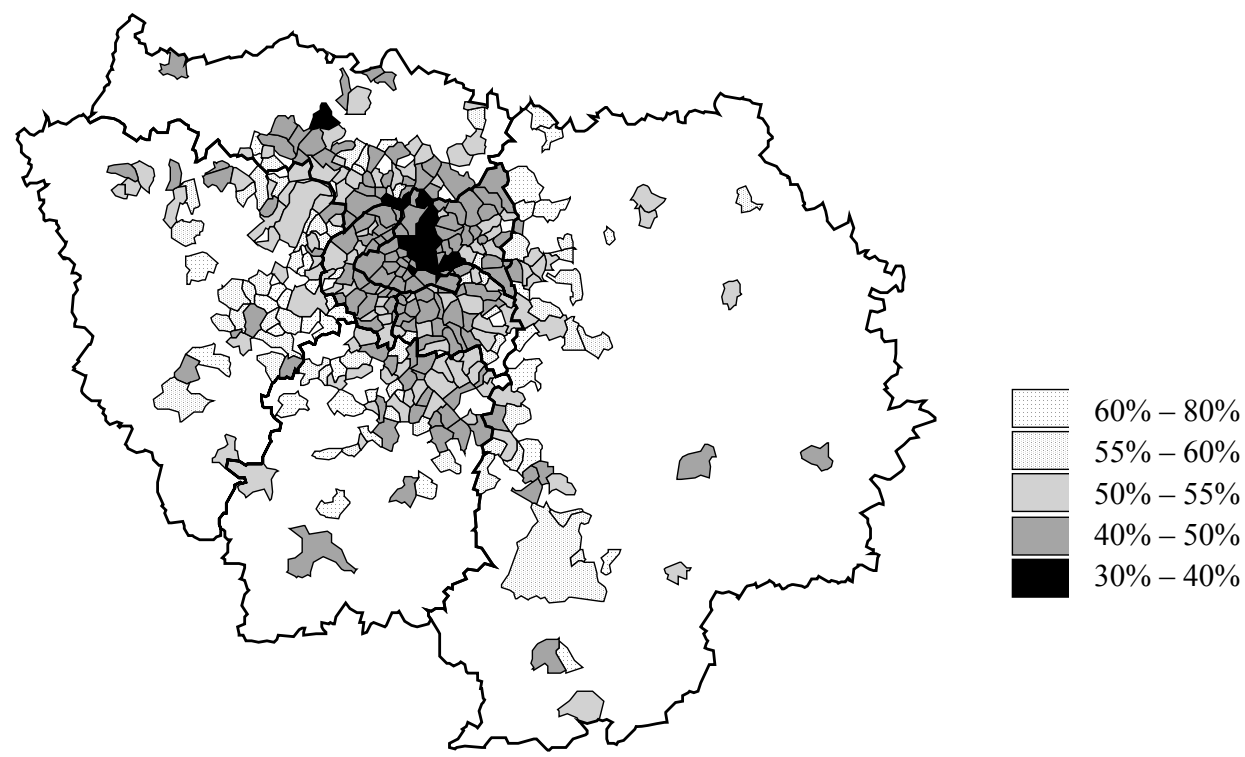

Source: constructed from the ANPE file.

Graph 6: Probability of leaving for non-employment before 24 months (model) for municipalities with at least 5,000 inhabitants

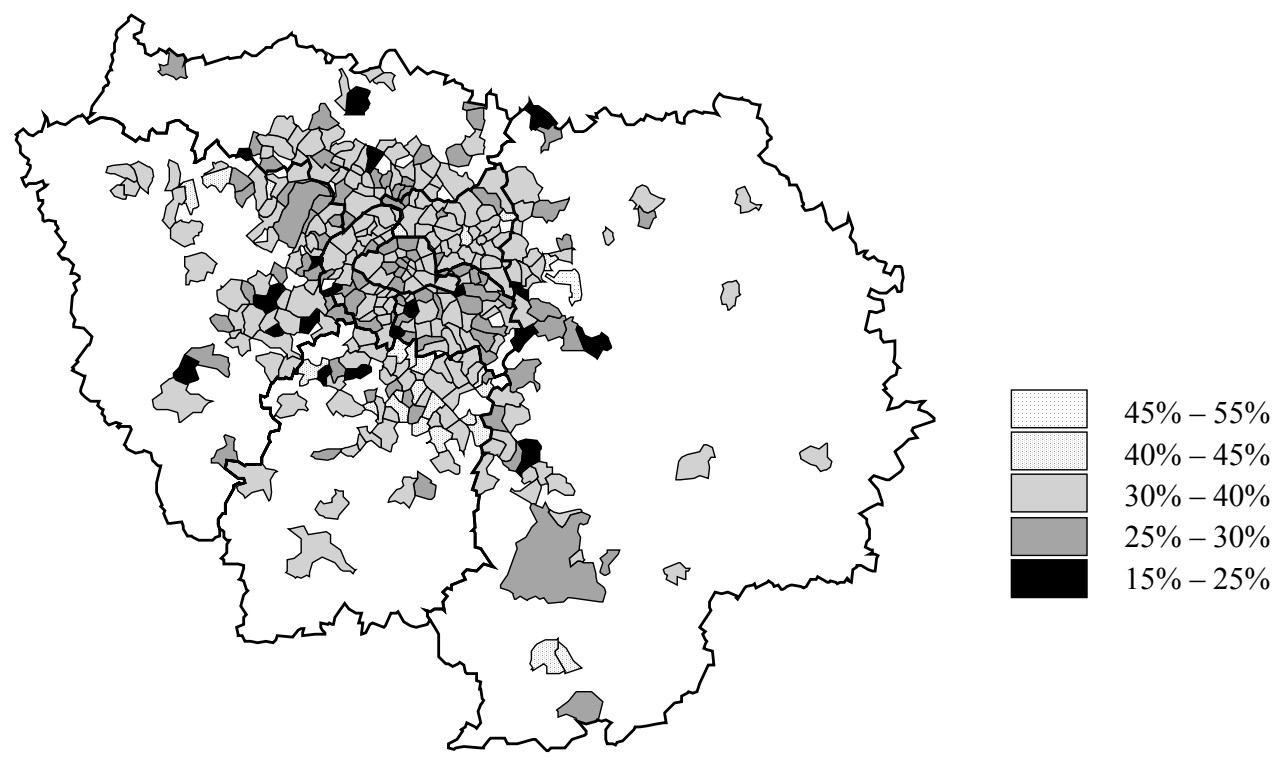


Graph 7: Municipality average of individual effects $X^{j} \beta$

as a function of log-integrated hazard at 24 months for exit to job

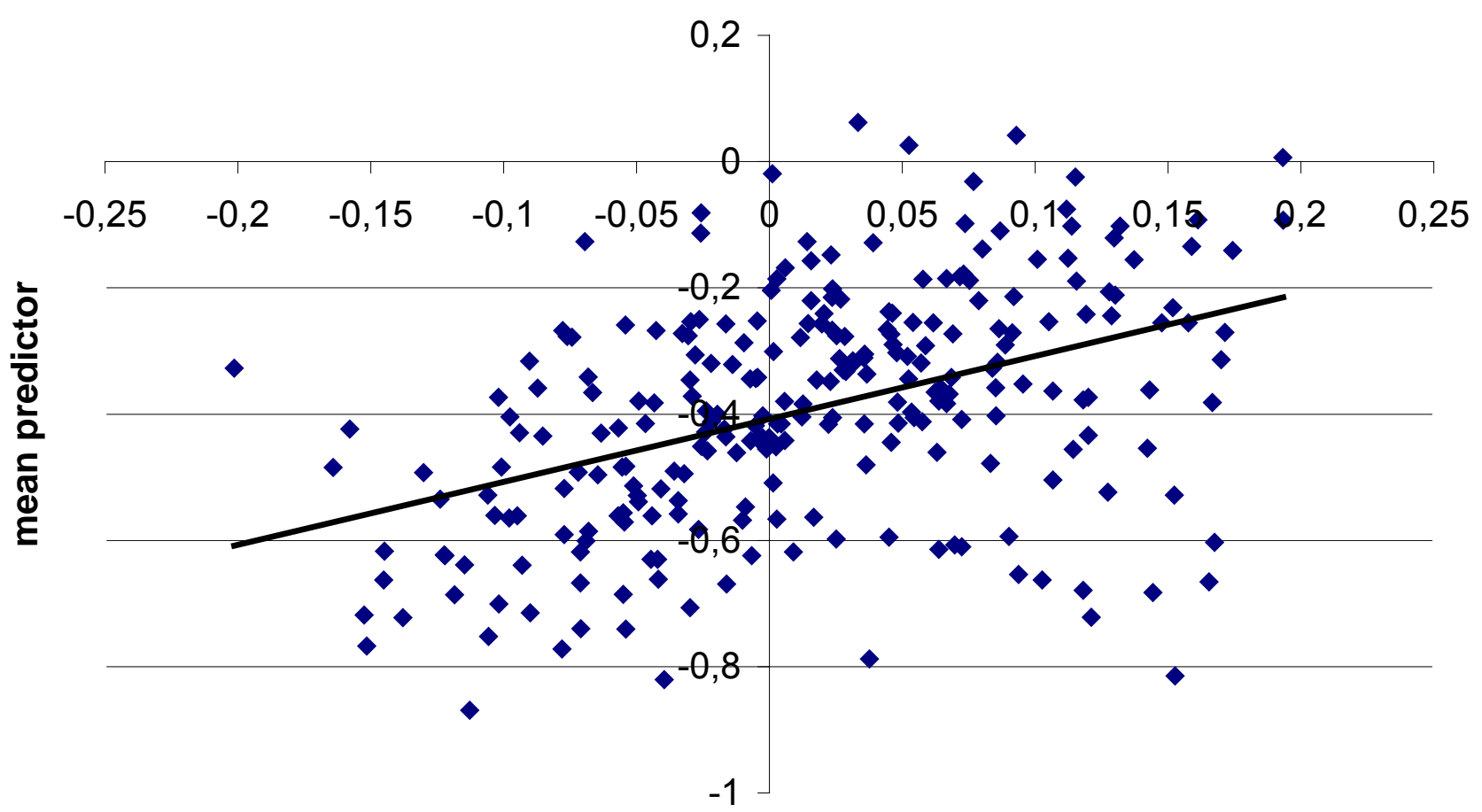

log-integrated hazard at 24 months 
Table 1: Spatial inequality indices for variables from the ANPE file

\begin{tabular}{|c|c|c|c|c|c|c|}
\hline Variables & Mean & q90/q10 & q90-q10 & Gini & $\begin{array}{l}\text { Coeff. of } \\
\text { variation }\end{array}$ & $\begin{array}{c}\text { Number } \\
\text { of obs. }\end{array}$ \\
\hline \multicolumn{7}{|l|}{ Exit types and unemployment spells } \\
\hline Exit to job & .280 & 1.734 & .152 & .121 & .224 & 1289 \\
\hline Exit to non-employment & .167 & 1.370 & .052 & .070 & 148 & 1289 \\
\hline Right-censoring & .553 & 1.322 & .152 & .218 & .426 & 1289 \\
\hline Duration if exit to job & 276 & 1.374 & 87 & .070 & 138 & 1254 \\
\hline Duration if exit to non-employment & 369 & 1.433 & 131 & .083 & .179 & 1156 \\
\hline Duration if right-censoring & 334 & 1.753 & 179 & 130 & .281 & 849 \\
\hline \multicolumn{7}{|l|}{ Characteristics of unemployed workers } \\
\hline Age & 32.610 & 1.080 & 2.499 & .017 & .032 & 1289 \\
\hline Male & .518 & 1.164 & .078 & .033 & .068 & 1289 \\
\hline Female & .482 & 1.177 & .078 & .035 & .073 & 1289 \\
\hline Single & .606 & 1.327 & .174 & .062 & .113 & 1289 \\
\hline Couple & .394 & 1.599 & .175 & .095 & .174 & 1289 \\
\hline 0 child & .613 & 1.352 & .185 & .065 & .116 & 1289 \\
\hline 1 child & .163 & 1.458 & .061 & .085 & .174 & 1289 \\
\hline 2 children & .124 & 1.875 & .074 & 135 & .264 & 1289 \\
\hline 3 children & .057 & 2.814 & .056 & .212 & .404 & 1289 \\
\hline 4 children & .023 & 5.281 & .032 & .306 & .569 & 1289 \\
\hline 5 children and more & .019 & 6.938 & .032 & .378 & .703 & 1289 \\
\hline French & .782 & 1.315 & .214 & .060 & .107 & 1289 \\
\hline European (other) & .064 & 2.636 & .061 & .209 & .402 & 1289 \\
\hline North African & .077 & 5.444 & .110 & .305 & .541 & 1289 \\
\hline African (other) & .045 & 5.665 & .063 & .303 & .531 & 1289 \\
\hline Other Nationality & .032 & 1.671 & .051 & .371 & .695 & 1289 \\
\hline No diploma & .239 & 3.942 & .315 & .285 & .513 & 1289 \\
\hline High School (excluding final year) & .165 & 1.636 & .079 & .106 & .205 & 1289 \\
\hline \multicolumn{7}{|l|}{ High school (final year and diploma) } \\
\hline and technical diploma & .327 & 2.199 & .231 & .152 & .272 & 1289 \\
\hline Secondary school & .269 & 2.455 & .226 & .179 & .314 & 1289 \\
\hline Disabled & .033 & 2.631 & .030 & .195 & .399 & 1289 \\
\hline
\end{tabular}

Source: constructed from the ANPE file, sample of workers whose unemployment spell started between January 1996 and June 1996. All indices are weighted by the number of unemployed workers. 
Table 2: Spatial inequality indices for measures of segregation and job accessibility

\begin{tabular}{|c|c|c|c|c|c|c|}
\hline Variables & Mean & q90/q10 & q90-q10 & Gini & $\begin{array}{l}\text { Coeff. of } \\
\text { variation }\end{array}$ & $\begin{array}{l}\text { Number } \\
\text { of obs. }\end{array}$ \\
\hline \multicolumn{7}{|l|}{ Segregation variables } \\
\hline Unemployment rate & .116 & 2.408 & .100 & .196 & .355 & 1300 \\
\hline$\%$ French & .813 & 1.277 & .198 & .054 & .095 & 1300 \\
\hline$\%$ European (other) & .070 & 2.080 & .050 & .160 & .294 & 1300 \\
\hline$\%$ North African & .054 & 9.464 & .097 & .396 & .730 & 1300 \\
\hline$\%$ African (other) & .026 & 9.371 & .046 & .389 & .700 & 1300 \\
\hline$\%$ Other Nationality & .037 & 6.522 & .057 & .361 & .688 & 1300 \\
\hline \% No diploma & .399 & 1.895 & .248 & .130 & .227 & 1300 \\
\hline$\%$ Technical diploma & .192 & 2.526 & .156 & .175 & 311 & 1300 \\
\hline$\%$ High school & .148 & 1.453 & .054 & .076 & .137 & 1300 \\
\hline$\%$ University & .261 & 3.883 & .333 & .270 & .479 & 1300 \\
\hline \multicolumn{7}{|l|}{ Job-accessibility variables } \\
\hline $45 \mathrm{mn}$ job density by public transport & 1.062 & 2.995 & 1.009 & .211 & .459 & 1300 \\
\hline $45 \mathrm{mn}$ job density by car & .856 & 1.615 & .400 & .104 & .181 & 1300 \\
\hline
\end{tabular}


Table 3: Estimation results of the first-stage equation (SPLE)

\begin{tabular}{|c|c|c|}
\hline Variables & Job & Non-employment \\
\hline Age /100 & $\begin{array}{c}-2.9289^{* * *} \\
(.2801)\end{array}$ & $\begin{array}{c}-9.0729^{* * *} \\
(.3253)\end{array}$ \\
\hline (Age/100) squared & $\begin{array}{c}1.210^{* * *} \\
(.387)\end{array}$ & $\begin{array}{c}11.330^{* * *} \\
(.442)\end{array}$ \\
\hline Female & $\begin{array}{c}-.1819^{* * *} \\
(.0060)\end{array}$ & $\begin{array}{l}.3486^{\star * *} \\
(.0079)\end{array}$ \\
\hline Couple & $\begin{array}{l}.1089^{* * *} \\
(.0077)\end{array}$ & $\begin{array}{l}.0710^{* * *} \\
(.0094)\end{array}$ \\
\hline 1 child & $\begin{array}{c}-.0815^{* * *} \\
(.0093)\end{array}$ & $\begin{array}{l}.0834^{* * *} \\
(.0110)\end{array}$ \\
\hline 2 children & $\begin{array}{c}-.0266^{* *} \\
(.0106)\end{array}$ & $\begin{array}{l}.0375^{\star \star *} \\
(.0130)\end{array}$ \\
\hline 3 children & $\begin{array}{c}-.1312^{* * *} \\
(.0149)\end{array}$ & $\begin{array}{l}.0352^{* *} \\
(.0174)\end{array}$ \\
\hline 4 children & $\begin{array}{c}-.1823^{* * *} \\
(.0245)\end{array}$ & $\begin{array}{l}.0428^{*} \\
(.0260)\end{array}$ \\
\hline 5 children and more & $\begin{array}{c}-.2425^{\star * *} \\
(.0299)\end{array}$ & $\begin{array}{l}.0852^{* * *} \\
(.0281)\end{array}$ \\
\hline European & $\begin{array}{c}-.0510^{* * *} \\
(.0124)\end{array}$ & $\begin{array}{c}-.1732^{* * *} \\
(.0168)\end{array}$ \\
\hline Maghrebine & $\begin{array}{c}-.4455^{* * *} \\
(.0143)\end{array}$ & $\begin{array}{c}-.0810^{* * *} \\
(.0154)\end{array}$ \\
\hline African (other) & $\begin{array}{c}-.6638^{* * *} \\
(.0209)\end{array}$ & $\begin{array}{l}-.0244 \\
(.0198)\end{array}$ \\
\hline Other Nationality & $\begin{array}{c}-.5629^{* * *} \\
(.0231)\end{array}$ & $\begin{array}{l}.0248 \\
(.0224)\end{array}$ \\
\hline High School (first grade) & $\begin{array}{c}-.2296^{* * *} \\
(.0089)\end{array}$ & $\begin{array}{c}-.0970^{* * *} \\
(.0118)\end{array}$ \\
\hline High school (other grade) and technical diploma & $\begin{array}{c}-.3349^{* * *} \\
(.0078)\end{array}$ & $\begin{array}{c}-.2176^{* * *} \\
(.0107)\end{array}$ \\
\hline Secondary school & $\begin{array}{c}-.5872^{* * *} \\
(.0095)\end{array}$ & $\begin{array}{c}-.4252^{* * *} \\
(.0119)\end{array}$ \\
\hline Disabled & $\begin{array}{c}-03837^{* * *} \\
(.0197)\end{array}$ & $\begin{array}{l}.4653^{* * *} \\
(.0168)\end{array}$ \\
\hline Number of observations & \multicolumn{2}{|c|}{430,695} \\
\hline
\end{tabular}

***: significant at $1 \%$ level; **: significant at $5 \%$ level; *: significant at $10 \%$ level.

Monthly dummy variables were also included to control for seasonality but are not reported in the table. 
Table 4: Disparity indices at the municipality level

\begin{tabular}{|c|c|c|c|c|c|}
\hline Statistics on durations & Mean & P90 / P10 & P90 - P10 & Gini & $\begin{array}{l}\text { Coeff. of } \\
\text { variation }\end{array}$ \\
\hline \multicolumn{6}{|l|}{ Until exit to job } \\
\hline \multicolumn{6}{|l|}{ Survival at 6 months } \\
\hline Kaplan-Meier & .801 & 1.173 & .127 & .035 & .065 \\
\hline Model & .811 & 1.132 & .100 & .028 & .053 \\
\hline Multiplicative model & .811 & 1.135 & .103 & .027 & .055 \\
\hline \multicolumn{6}{|l|}{ Survival at 24 months } \\
\hline Kaplan-Meier & .533 & 1.503 & .213 & .088 & 164 \\
\hline Model & .537 & 1.426 & .188 & .076 & .143 \\
\hline Multiplicative model & .535 & 1.416 & .185 & .076 & .142 \\
\hline \multicolumn{6}{|l|}{ Until exit to non employment } \\
\hline \multicolumn{6}{|l|}{ Survival at 6 months } \\
\hline Kaplan-Meier & .893 & 1.059 & .051 & 012 & .027 \\
\hline Model & .896 & 1.049 & .043 & .011 & .024 \\
\hline Multiplicative model & .894 & 1.068 & .059 & .011 & .037 \\
\hline \multicolumn{6}{|l|}{ Survival at 24 months } \\
\hline Kaplan-Meier & .681 & 1.200 & .123 & .039 & .093 \\
\hline Model & .686 & 1.175 & .109 & .036 & .075 \\
\hline Multiplicative model & .683 & 1.175 & .110 & .036 & .087 \\
\hline
\end{tabular}

Table 5: Variance analysis at the municipality level

\begin{tabular}{|c|c|c|c|c|}
\hline \multirow[b]{3}{*}{$X^{j} \beta$} & \multicolumn{2}{|c|}{ Exit to Job } & \multicolumn{2}{|c|}{ Exit to non-employment } \\
\hline & Variance & $\begin{array}{c}\text { Correlation } \\
\text { With } X^{j} \beta\end{array}$ & Variance & $\begin{array}{c}\text { Correlation } \\
\text { With } X^{j} \beta\end{array}$ \\
\hline & .0068 & 1 & .0016 & 1 \\
\hline $\mathrm{InH}_{\mathrm{k}} 6$ & .0750 & 668 & .0387 & .127 \\
\hline $\mathrm{InH}_{\mathrm{m}} 6$ & .0556 & 468 & .0381 & -.081 \\
\hline $\operatorname{lnH}_{m} 6+X^{j} \beta$ & .0805 & 679 & .0385 & .126 \\
\hline $\mathrm{InH}_{\mathrm{mm}} 6$ & .0499 & .437 & .0309 & -.030 \\
\hline $\operatorname{lnH}_{m m} 6+X^{j} \beta$ & .0728 & .667 & .0322 & .197 \\
\hline $\mathrm{InH}_{\mathrm{k}} 12$ & .0702 & 693 & .0358 & .177 \\
\hline $\operatorname{lnH} \mathrm{H}_{\mathrm{m}} 12$ & .0508 & .490 & .0346 & -.049 \\
\hline $\mathrm{InH}_{\mathrm{m}}^{1} 12+\mathrm{X}^{\mathrm{j}} \beta$ & .0757 & .700 & .0355 & .167 \\
\hline $\mathrm{InH}_{\mathrm{mm}} 12$ & .0449 & .435 & .0342 & -.024 \\
\hline $\mathrm{InH}_{\mathrm{mm}} 12+\mathrm{X}^{\mathrm{j}} \beta$ & .0726 & .666 & .0355 & .193 \\
\hline $\mathrm{InH}_{\mathrm{k}} 24$ & .0602 & 646 & .0374 & .149 \\
\hline $\mathrm{InH}_{\mathrm{m}} 24$ & .0465 & .387 & .0372 & -.087 \\
\hline $\mathrm{InH}_{\mathrm{m}} 24+X^{\mathrm{j}} \beta$ & .0669 & 639 & .0375 & .123 \\
\hline $\mathrm{InH}_{\mathrm{mm}} 24$ & .0481 & .435 & .0340 & .034 \\
\hline $\mathrm{InH}_{\mathrm{mm}} 24+\mathrm{X}^{\mathrm{j}} \beta$ & .0705 & .668 & .0352 & .035 \\
\hline
\end{tabular}

Fixed effects in the multiplicative model are computed using 8 intervals of 90 days and one interval covering the remaining days.

$\mathrm{X}^{\mathrm{j}} \beta$ : average effect of individual explanatory variables at the municipality level. $\ln \mathrm{H}_{\mathrm{k}} \mathrm{T}$ : $\log$ of integrated hazard at $\mathrm{T}$ days using the KaplanMeyer estimator. $\ln \mathrm{H}_{\mathrm{m}} \mathrm{T}$ : $\log$ of integrated hazard at $\mathrm{T}$ days for the model. $\ln \mathrm{H}_{\mathrm{mm}} \mathrm{T}$ : $\log$ of integrated hazard at $\mathrm{T}$ days for the model under the multiplicative assumption for the hazard rate. Statistics are computed weighting municipalities by their number of unemployed workers. 
Table 6: Regressions of town fixed effects (for exit to job) on municipality variables

\begin{tabular}{|c|c|c|c|}
\hline & $(1)$ & $(2)$ & $(3)$ \\
\hline Constant & $\begin{array}{l}-6.717^{* * *} \\
(.120)\end{array}$ & $\begin{array}{l}-6.147^{* * *} \\
(.035)\end{array}$ & $\begin{array}{l}-6.644^{* * *} \\
(.121)\end{array}$ \\
\hline Proportion of technical diplomas & $\begin{array}{c}1.861^{* * *} \\
(.337)\end{array}$ & & $\begin{array}{c}1.966^{* * *} \\
(.338)\end{array}$ \\
\hline Proportion of high school diplomas & $\begin{array}{l}-.078 \\
(.384)\end{array}$ & & $\begin{array}{l}-.260 \\
(.386)\end{array}$ \\
\hline Proportion of college diplomas & $\begin{array}{l}.099 \\
(.178)\end{array}$ & & $\begin{array}{l}.354^{*} \\
(.192)\end{array}$ \\
\hline Proportion of European (other) & $\begin{array}{l}-1.394^{* * *} \\
(.246)\end{array}$ & & $\begin{array}{l}-1.402^{* * *} \\
(.245)\end{array}$ \\
\hline Proportion of North Africans & $\begin{array}{l}-1.756^{* * *} \\
(.220)\end{array}$ & & $\begin{array}{l}-1.344^{* * *} \\
\quad(.250)\end{array}$ \\
\hline Proportion of Africans (other) & $\begin{array}{l}-3.775^{* * *} \\
(.513)\end{array}$ & & $\begin{array}{l}-3.872^{* * *} \\
(.512)\end{array}$ \\
\hline Proportion of other nationalities & $\begin{array}{l}-.458^{*} \\
(.246)\end{array}$ & & $\begin{array}{l}-.491^{* *} \\
(.245)\end{array}$ \\
\hline $\begin{array}{l}\text { Job density within } 45 \text { mins by public } \\
\text { transport }\end{array}$ & & $\begin{array}{c}-.092^{* * *} \\
(.016)\end{array}$ & $\begin{array}{l}.000 \\
(.012)\end{array}$ \\
\hline $\begin{array}{l}\text { Job density within } 45 \text { mins by private } \\
\text { transport }\end{array}$ & & $\begin{array}{c}-.517^{* * *} \\
(.047)\end{array}$ & $\begin{array}{l}-.176^{* * *} \\
(.051)\end{array}$ \\
\hline Number of observation & 1254 & 1254 & 1254 \\
\hline Weighted number of observations & 430602 & 430602 & 430602 \\
\hline Error rate & .468 & .246 & .473 \\
\hline Pseudo-R ${ }^{2}$ & .724 & .259 & .730 \\
\hline
\end{tabular}


Table A1: Descriptive statistics on variables used in the study

\begin{tabular}{|c|c|c|c|c|c|}
\hline Variable & $\begin{array}{l}\text { Number } \\
\text { of obs. }\end{array}$ & Mean & $\begin{array}{l}\text { Standard } \\
\text { deviation }\end{array}$ & Minimum & Maximum \\
\hline \multicolumn{6}{|l|}{ Exit types and unemployment spells } \\
\hline Exit to job & 430,695 & .280 & .449 & .000 & 1.000 \\
\hline Exit to non-employment & 430,695 & .167 & .373 & .000 & 1.000 \\
\hline Right-censoring & 430,695 & .672 & .470 & .000 & 1.000 \\
\hline Duration if exit to job & 120,502 & 273 & 337 & 1 & 2818 \\
\hline Duration if exit to non-employment & 71,807 & 368 & 452 & 1 & 2813 \\
\hline Duration if right-censoring & 238,386 & 287 & 378 & 1 & 2829 \\
\hline \multicolumn{6}{|l|}{$\begin{array}{l}\text { Characteristics of unemployed } \\
\text { workers }\end{array}$} \\
\hline Age & 430,695 & 32.610 & 9.222 & 16.000 & 54.000 \\
\hline Male & 430,695 & .518 & .500 & .000 & 1.000 \\
\hline Female & 430,695 & .482 & .500 & .000 & 1.000 \\
\hline Single & 430,695 & .606 & .489 & .000 & 1.000 \\
\hline Couple & 430,695 & .394 & .489 & .000 & 1.000 \\
\hline 0 child & 430,695 & .613 & .487 & .000 & 1.000 \\
\hline 1 child & 430,695 & .163 & .369 & .000 & 1.000 \\
\hline 2 children & 430,695 & .124 & .330 & .000 & 1.000 \\
\hline 3 children & 430,695 & .057 & .233 & .000 & 1.000 \\
\hline 4 children & 430,695 & .023 & .150 & .000 & 1.000 \\
\hline 5 children and more & 430,695 & .019 & .137 & .000 & 1.000 \\
\hline French & 430,695 & .782 & .413 & .000 & 1.000 \\
\hline European (other) & 430,695 & .064 & .245 & .000 & 1.000 \\
\hline North African & 430,695 & .077 & .267 & .000 & 1.000 \\
\hline African (other) & 430,695 & .045 & .207 & .000 & 1.000 \\
\hline Other Nationality & 430,695 & .032 & .175 & .000 & 1.000 \\
\hline No diploma & 430,695 & .239 & .427 & .000 & 1.000 \\
\hline High School (excluding final year) & 430,695 & .165 & .371 & .000 & 1.000 \\
\hline \multicolumn{6}{|l|}{ High school (final year and diploma) } \\
\hline and technical diploma & 430,695 & 327 & .469 & .000 & 1.000 \\
\hline Secondary school & 430,695 & .269 & .443 & .000 & 1.000 \\
\hline Disabled & 430,695 & .033 & .178 & .000 & 1.000 \\
\hline \multicolumn{6}{|l|}{ Segregation variables } \\
\hline Unemployment rate & 430,695 & .127 & .043 & .000 & .246 \\
\hline$\%$ French & 430,695 & .794 & .078 & .569 & 1.000 \\
\hline$\%$ European (other) & 430,695 & .071 & .020 & .000 & .265 \\
\hline$\%$ North African & 430,695 & .064 & .041 & .000 & .218 \\
\hline$\%$ African (other) & 430,695 & .030 & .019 & .000 & .086 \\
\hline$\%$ Other Nationality & 430,695 & .041 & .027 & .000 & .230 \\
\hline$\%$ No diploma & 430,695 & .412 & .091 & .202 & .663 \\
\hline$\%$ Technical diploma & 430,695 & .191 & .057 & .040 & .402 \\
\hline$\%$ High school & 430,695 & .145 & .020 & .000 & .266 \\
\hline \% University & 430,695 & .252 & .123 & .030 & .571 \\
\hline \multicolumn{6}{|l|}{ Job-accessibility variables } \\
\hline $45 \mathrm{mn}$ job density by public transport & 430,695 & 1.085 & .436 & .076 & 19.920 \\
\hline $45 \mathrm{mn}$ job density by car & 430,695 & .860 & .152 & .152 & 1.200 \\
\hline
\end{tabular}

